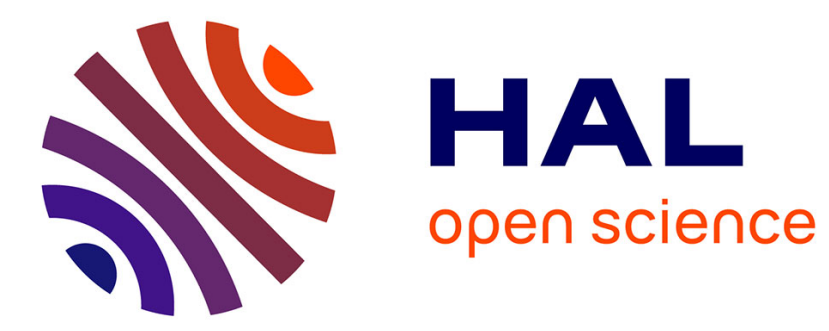

\title{
Relationship between heating atmosphere and copper foil impurities during graphene growth via low pressure chemical vapor deposition
}

\author{
Yasemin Çelik, Walter Escoffier, Yang Ming, Emmanuel Flahaut, Ender \\ Suvaci
}

\section{To cite this version:}

Yasemin Çelik, Walter Escoffier, Yang Ming, Emmanuel Flahaut, Ender Suvaci. Relationship between heating atmosphere and copper foil impurities during graphene growth via low pressure chemical vapor deposition. Carbon, 2016, vol. 109, pp. 529-541. 10.1016/j.carbon.2016.08.057 . hal-01538550

\author{
HAL Id: hal-01538550 \\ https://hal.science/hal-01538550
}

Submitted on 13 Jun 2017

HAL is a multi-disciplinary open access archive for the deposit and dissemination of scientific research documents, whether they are published or not. The documents may come from teaching and research institutions in France or abroad, or from public or private research centers.
L'archive ouverte pluridisciplinaire HAL, est destinée au dépôt et à la diffusion de documents scientifiques de niveau recherche, publiés ou non, émanant des établissements d'enseignement et de recherche français ou étrangers, des laboratoires publics ou privés. 


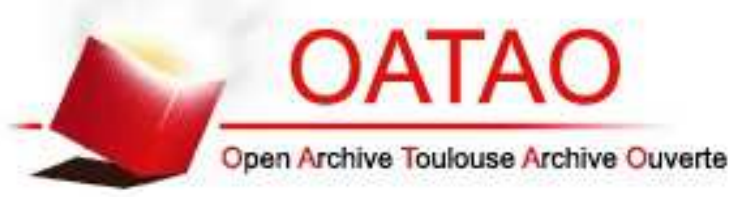

\section{Open Archive TOULOUSE Archive Ouverte (OATAO)}

OATAO is an open access repository that collects the work of Toulouse researchers and makes it freely available over the web where possible.

This is an author-deposited version published in : http://oatao.univ-toulouse.fr/ Eprints ID : 16772

To link to this article : DOI:10.1016/j.carbon.2016.08.057

URL : http://dx.doi.org/10.1016/j.carbon.2016.08.057

To cite this version : Çelik, Yasemin and Escoffier, Walter and

Yang, Ming and Flahaut, Emmanuel and Suvac1, Ender Relationship between heating atmosphere and copper foil impurities during graphene growth via low pressure chemical vapor deposition. (2016) Carbon, vol. 109. pp. 529-541. ISSN 0008-6223

Any correspondence concerning this service should be sent to the repository administrator: staff-oatao@ listes-diff.inp-toulouse.fr 


\title{
Relationship between heating atmosphere and copper foil impurities during graphene growth via low pressure chemical vapor deposition
}

\author{
Yasemin Çelik ${ }^{\text {a, b, *, }}$, Walter Escoffier ${ }^{c}$, Ming Yang ${ }^{\mathrm{c}}$, Emmanuel Flahaut ${ }^{\mathrm{b}}$, Ender Suvacı ${ }^{\text {a }}$ \\ a Anadolu University, Department of Materials Science and Engineering, 26480 Eskisehir, Turkey \\ b CIRIMAT, Université de Toulouse, CNRS, INPT, UPS, UMR CNRS-UPS-INP N5085, Université Toulouse 3 Paul Sabatier, Bât. CIRIMAT, 118, route de Narbonne, \\ 31062 Toulouse cedex 9, France \\ ${ }^{c}$ Laboratoire National des Champs Magnétiques Intenses, INSA UPS, CNRS UPR 3228, Université de Toulouse, 143 avenue de Rangueil, 31400 Toulouse, \\ France
}

\begin{abstract}
A B S T R A C T
Low-pressure chemical vapor deposition synthesis of graphene films on two different $\mathrm{Cu}$ foils, with different surface oxygen and carbon contents, was performed by controlling $\mathrm{H}_{2}$ and/or Ar flow rates during heating. The influences of heating atmosphere on the final impurity level, quality of the synthesized graphene films and thickness uniformity were investigated depending on $\mathrm{Cu}$ foil impurities. Heating of carbon-rich, but oxygen-poor $\mathrm{Cu}$ foil in $\mathrm{H}_{2}$ environment resulted in covering the foil surface by residual carbon which then acted as active sites for multilayer graphene growth. Ar-only flow was required during heating to promote high quality graphene growth on this foil. On carbon-poor, but oxygen-rich $\mathrm{Cu}$ foil high quality graphene growth was promoted when the heating was carried out under $\mathrm{Ar} / \mathrm{H}_{2}$ environment. Almost no carbon residues were observed on this foil even under $\mathrm{H}_{2}$ only flow during heating. The heating atmosphere affected not only graphene growth, but also the type and amount of impurities formed on the surface. $\mathrm{H}_{2}$ and $\mathrm{Ar} / \mathrm{H}_{2}$ heating resulted in the formation of spherical nanometer-sized impurities, while irregular-shaped, large (a few $\mu \mathrm{m}) \mathrm{SiO}_{2}$ impurities were observed when Ar alone was used during heating. Quality of the grown films was tested by Quantum Hall Effect measurements.
\end{abstract}

\section{Introduction}

Graphene is a single atom-thick plane of carbon atoms arranged in a two-dimensional honeycomb lattice. In spite of having an atomic thickness, it is the strongest thermodynamically stable material ever known [1]. It is an excellent electrical conductor, which shows room temperature ballistic transport [2] and has an extremely high intrinsic thermal conductivity at room temperature, which is among the highest of any known materials for sufficiently large, suspended flakes [3]. Due to these unique properties, graphene is a promising material for many applications such as field effect transistors, transparent electrodes, sensors, energy storage systems and nanocomposites. However, production of high quality graphene-based materials at industrial scale is a prerequisite for

\footnotetext{
* Corresponding author. Anadolu University, Department of Materials Science and Engineering, 26480 Eskisehir, Turkey.

E-mail address: ybozkaya@anadolu.edu.tr (Y. Çelik).
}

making the potential applications of graphene real. Chemical vapor deposition (CVD) is a promising method for large-area graphene production at a large scale with low defects, good uniformity and controlled number of graphene layers. The graphene films made on metal film or foil surfaces can be easily removed and transferred onto dielectric substrates. This enables one to produce large area, planar graphene films with relatively low defect density and is well-suited for flexible transparent electrodes and electronic applications where the growth can be patterned precisely in combination with lithographical methods.

Graphene growth on $\mathrm{Cu}$ foils has shown great promise for largearea, single layer graphene [4]; however, there are also some challenges. The quality, thickness and uniformity of CVD-grown graphene films depend on various parameters such as gas flow rates, growth temperature and time, pressure during the entire growth process, cooling rate, etc. The surface morphology and purity (amount of impurities) of the Cu foil both play a critical role in the graphene growth, as well. Disorder, defects and impurities originating from both the metal catalyst itself and/or from the 
synthesis process (i.e., from synthesis parameters and transfer process) act as active sites for graphene nucleation, enhancing the catalytic activity of the $\mathrm{Cu}$ surface and leading to thickness nonuniformities across the grown film [5]. These surface irregularities may also affect the mobility of the CVD-synthesized graphene significantly. It was shown that high quality and uniform CVDgrown graphene films exhibit anomalous Quantum Hall Effect (QHE) at low temperature and high magnetic field [6]. However, the structural characteristics and disorders at the microscopic and macroscopic scales have strong influence on transport properties of graphene. The mobility of CVD-grown graphene is limited by disorder originating from both growth and transfer processes. In order to improve the thickness uniformity and enhance the transport properties of CVD grown graphene, the amount of disorder, defects or impurities has to be eliminated or at least minimized by controlling the process parameters (such as growth temperature, time, pressure and gas flow rates during the entire CVD process), transfer route and $\mathrm{Cu}$ foil properties. Pre-cleaning $\mathrm{Cu}$ foil surface using chemical etchants (i.e., acid solutions), electropolishing and hydrogen annealing have commonly been applied in order to provide a clean and flat surface by reducing surface irregularities. However, it should be taken into account that the amount and type of $\mathrm{Cu}$ foil impurities may show variations from batch to batch or depending on supplier which make it difficult to remove these impurities equally by standard cleaning routes, and this may cause irreproducibility issues [7]. In recent years, several studies have focused on reducing graphene nucleation density by controlling $\mathrm{H}_{2}$ and/or $\mathrm{Ar}$ partial pressures during pre-graphene growth steps (heating up to growth temperature and annealing) [8-12]. Gan and Luo [8] observed that heating chemically etched Cu foil in Ar only environment produced a rather rough and uniform surface with copper oxide nanoparticles which were then reduced to copper nanoparticles with size of several to tens of nanometers during annealing in $\mathrm{Ar} / \mathrm{H}_{2}$ environment. They suggested that heating in $\mathrm{Ar}$ only environment is crucial for introducing selective nucleation centers in the graphene growth step, and consequently enabling the control of graphene sizes. Zhou et al. [9] showed that graphene nucleation density was reduced by nearly two orders of magnitude when the $\mathrm{Cu}$ foil was heated/annealed in pure Ar gas compared with that heated/annealed in the $\mathrm{Ar} / \mathrm{H}_{2}$ mixture. The authors attributed graphene nucleation reduction to higher nucleation barrier on the copper oxide compared with the fresh copper surface. Hao et al. [10] found that graphene nucleation density was reduced by introducing oxygen into the CVD chamber just before introduction of methane. This enabled growth of $\mathrm{cm}$-scale graphene domains. The authors attributed the nucleation density reduction to passivation of $\mathrm{Cu}$ surface active sites by the oxygen on the Cu surface. Jung et al. [11] performed atmospheric pressure CVD growth of graphene domains on $\mathrm{Cu}$ foil using various volume ratios of $\mathrm{H}_{2}$ and $\mathrm{Ar}$ during annealing in order to investigate the influence of partial pressure of $\mathrm{H}_{2}$ during annealing on the growth rate and shape of the graphene domains. It was observed that the mean size and density of graphene domains increased with an increase in hydrogen partial pressure during the annealing time. The authors also reported synthesis of snowflake-shaped carbon aggregates when only $\mathrm{H}_{2}$ was used during the annealing process [11]. Shin and Kong [12] investigated the effect of hydrogen introduction in each step of atmospheric pressure CVD process and found that a pristine graphene monolayer was obtained when no hydrogen was used in the process. These studies have revealed the critical role of pregraphene growth atmosphere on graphene nucleation density and domain size (consequently on graphene quality). However, the reported conditions for obtaining optimum graphene quality show variations which could arise from differences in as-received $\mathrm{Cu}$ foil characteristics (surface morphology and purity) used in these studies. Therefore, it is crucial to understand the relation between $\mathrm{Cu}$ foil impurities and heating and/or annealing atmosphere(s), and its effect on graphene growth and quality.

The objective of this study was to perform low-pressure CVD growth experiments of graphene films on two different $\mathrm{Cu}$ foils belonging to two different batches of the same commercial source by controlling the $\mathrm{H}_{2}$ and/or Ar flow rates during heating in order to investigate the influence of heating atmosphere on the final impurity level, quality of the synthesized graphene films and thickness uniformity depending on copper foil impurities. The electrical characterization of the graphene films transferred onto $\mathrm{SiO}_{2} / \mathrm{Si}$ substrates was performed at low temperature under high magnetic field, in the Quantum Hall regime which constitutes a special hallmark of graphene in order to test the graphene quality.

\section{Experimental procedure}

\subsection{Graphene synthesis, transfer process and characterization}

Graphene synthesis was carried out in a commercial CVD system with a 4 inch quartz tube inside a horizontal tube furnace (EasyTube 3000 Ext., First Nano, USA) equipped with a screw dry vacuum pump (Busch BA100 A) which allows the control of the pressure in the reaction chamber between 0.1 and 700 Torr. The system also contains a dedicated secondary pump to ensure effective seal in the reaction chamber. Graphene growth was performed on $\mathrm{Cu}$ foils as a catalytic substrate. $25 \mu \mathrm{m}$ thick and $99.8 \%$ pure Alfa Aesar foils with the same lot number (13382), but supplied from two different sources at different times (i.e., from different batches) were used as catalysts. The X-ray photoelectron spectroscopy (XPS) analysis of the as-received foils was performed using a Thermo Scientific Thermoelectron K-Alpha apparatus. The photoelectron emission spectra were recorded using $\mathrm{Al}-\mathrm{K}_{\alpha}$ radiation $(\mathrm{h} v=1486.6 \mathrm{eV})$ from a monochromatized source. The X-ray spot diameter on the sample surface was $400 \mu \mathrm{m}$. The pass energy was fixed at $30 \mathrm{eV}$. The spectrometer energy calibration was performed using the $\mathrm{Au} 4 \mathrm{f}^{7 / 2}(83.9 \pm 0.1 \mathrm{eV})$ and $\mathrm{Cu} 2 \mathrm{p}^{3 / 2}$ $(932.8 \pm 0.1 \mathrm{eV})$ photoelectron lines. The background signal was removed using the Shirley method [13]. Atomic concentrations were determined from photoelectron peak areas using the atomic sensitivity factors reported by Scofield [14] and taking into account the transmission function of the analyzer. This function was determined at different pass energies from Ag 3d and Ag MNN peaks collected on a silver standard. XPS analysis indicated the presence of C, N, O and Cu elements on the surface of the 'CROP' foil, and $\mathrm{P}, \mathrm{C}, \mathrm{Ca}, \mathrm{O}$ and $\mathrm{Cu}$ elements on the surface of the 'CPOR' foil (see Supplementary Information, Figs. S1 and S2). The carbon and oxygen contents of these foils exhibited significant differences (Insets in Figs. S1 and S2). Accordingly, the relatively carbon-rich, but relatively oxygen-poor foil was denoted as 'CROP' and relatively carbon-poor, but relatively oxygen-rich foil was denoted as 'CPOR'. Table 1 shows the sample naming according to CVD synthesis conditions and pre-cleaning type of the $\mathrm{Cu}$ foils.

Prior to loading the $\mathrm{Cu}$ foils into the reaction chamber, they were cleaned using acetone, deionized (DI) water, acetic acid (glacial$100 \%)$ or nitric acid $(5.4(\mathrm{w} / \mathrm{w}))$, DI water, acetone and isopropyl alcohol, subsequently. After loading the samples into the chamber, the system was purged with Ar gas (purity 99.999\%) and a leak test was performed at base pressure with a leak-back rate below 0.05 Torr per minute. Then, the sample was heated from room temperature to $1000{ }^{\circ} \mathrm{C}$ at a pressure of 0.5 Torr (unless otherwise stated). Heating was performed under different atmospheres such as $\mathrm{Ar}, \mathrm{Ar} / \mathrm{H}_{2}$ or $\mathrm{H}_{2}$ (purity 99.999\%) to clarify the effect of heating atmosphere on graphene growth and graphene quality. For the annealing step, the system was maintained at $1000{ }^{\circ} \mathrm{C}$ for $30 \mathrm{~min}$ 
Table 1

The LPCVD grown graphene samples synthesized under different conditions.

\begin{tabular}{|c|c|c|c|c|}
\hline Samples & Pre-cleaning & Heating $\left(\mathrm{Ar}-\mathrm{H}_{2} \mathrm{sccm}\right)$ & Annealing $\left(\mathrm{H}_{2} \mathrm{sccm}\right)$ & Growth $\left(\mathrm{H}_{2}: \mathrm{CH}_{4} \mathrm{sccm}\right)$ \\
\hline CROP1 & Acetic acid & $0: 300$ & 300 & $100: 20$ \\
\hline CROP2 & Acetic acid & $200: 100$ & 300 & $100: 20$ \\
\hline CROP3 & Acetic acid & Hot load at $1000{ }^{\circ} \mathrm{C}$ & 300 & $100: 20$ \\
\hline CROP4 & Acetic acid & 200:0 & 300 & $100: 20$ \\
\hline CROP4-MC & Mechanical cleaning + acetic acid & 200:0 & 300 & $100: 20$ \\
\hline CPOR1 & Acetic acid & 0:300 & 300 & $100: 20$ \\
\hline CPOR2 & Acetic acid & $200: 100$ & 300 & $100: 20$ \\
\hline CPOR3 & Acetic acid & $200: 100$ & 300 & $100: 17$ \\
\hline CPOR4 & Acetic acid & $200: 0$ & 300 & $100: 20$ \\
\hline CPOR3-MC & Mechanical cleaning + acetic acid & 200:100 (0.3 Torr) & 300 (0.2 Torr) & 100:17 \\
\hline CPOR3-NA & Mechanical cleaning + nitric acid & $200: 100$ (0.3 Torr) & 300 (0.2 Torr) & $100: 17$ \\
\hline
\end{tabular}

Annealing: $1000{ }^{\circ} \mathrm{C}, 30 \mathrm{~min}, 300 \mathrm{sccm} \mathrm{H}$

Growth: $1000^{\circ} \mathrm{C}, 5 \mathrm{~min}$.

Cooling: Hot-unload at $940{ }^{\circ} \mathrm{C}$ under $100 \mathrm{sccm} \mathrm{H}_{2}$.

Pressure is 0.5 Torr in all the process steps unless otherwise stated.

under 300 standard cubic centimeters per minute ( $\mathrm{sccm}$ ) $\mathrm{H}_{2}$ flow at 0.5 Torr (unless otherwise stated) in order to reduce any oxide layer, to remove organic residues such as oil contaminations, lubricants, etc., originating from metal processing and to obtain $\mathrm{Cu}$ grains as large as possible. After annealing, $\mathrm{H}_{2}$ flow rate was decreased to 100 sccm and $20 \mathrm{sccm} \mathrm{CH}_{4}$ (purity 99.995\%) (Unless otherwise stated) was introduced into the system as the carbon source for graphene growth for $5 \mathrm{~min}$ at 0.5 Torr. The system was then cooled down to $940{ }^{\circ} \mathrm{C}$ and the sample was unloaded from the reaction chamber for a fast cooling. The process parameters are summarized in Table 1.

After graphene growth, one side of the copper foil was spincoated with $\sim 500 \mathrm{~nm}$-thick polymethyl-methacrylate (PMMA C4 950, Microchem Corp.) by using Specialty Coating Systems G3P-8 spin coater. The sample was then let for drying overnight in air. Since graphene is grown on both sides of the $\mathrm{Cu}$ foil, the graphene layer on the backside of the foil was removed by oxygen plasma etching at $\sim 100 \mathrm{~W}$ for 3 min by Gala Instrumente Plasma Prep 2 equipment. Then, $\mathrm{Cu}$ was etched in $1 \mathrm{M} \mathrm{FeCl}_{3}$ solution for a few hours. Once the $\mathrm{Cu}$ was removed completely, the PMMA/graphene film was soaked in DI water (as the PMMA side up) in order to clean the residual $\mathrm{FeCl}_{3}$ solution. This step was repeated several times with refreshed DI water. The PMMA/graphene film was then soaked in $\mathrm{H}_{2} \mathrm{O} / \mathrm{H}_{2} \mathrm{O}_{2} / \mathrm{HCl}$ solution for $\sim 15 \mathrm{~min}$ in order to remove metalbased contaminants that arise from $\mathrm{Cu}$ etchants and followed by DI water rinsing [15]. The PMMA/graphene film was transferred onto a pre-cleaned $\mathrm{Si}$ wafer with a $300 \mathrm{~nm}$ thick $\mathrm{SiO}_{2}$ layer. After drying the sample overnight in air, it was baked at $150{ }^{\circ} \mathrm{C}$ in air for $30 \mathrm{~min}$ to improve the contact between the graphene film and the substrate, and to reduce the number of cracks, as suggested by Liang et al. [15]. The PMMA was removed by immersing the sample in acetone at $\sim 50{ }^{\circ} \mathrm{C}$. The sample was then rinsed with isopropyl alcohol and dried by $\mathrm{N}_{2}$ blowing.

As-grown graphene films on $\mathrm{Cu}$ foils and the transferred graphene films onto $\mathrm{SiO}_{2} / \mathrm{Si}$ substrate were characterized by field emission gun - scanning electron microscope (FEG-SEM, Supra 50 $\mathrm{VP})$. Energy-dispersive $\mathrm{x}$-ray spectroscopy (EDX) analyses of these samples were also performed. Optical microscopy and microRaman analyses of the graphene films were performed on a Renishaw Invia spectrometer using $532 \mathrm{~nm}$ laser $(2.33 \mathrm{eV})$ excitation and $100 \times$ objective lens. The laser power was kept below $1 \mathrm{~mW}$ in order to prevent sample damage. At least three Raman spectra were recorded at different spots for each sample. Raman measurements were performed on as-grown graphene films on $\mathrm{Cu}$ foils, as well as on transferred graphene films onto $\mathrm{SiO}_{2} / \mathrm{Si}$ substrate for some of the samples. Costa et al. [16] showed that the acquisition of Raman spectra of graphene on Cu substrates is a practical and fast way to characterize as-grown graphene on $\mathrm{Cu}$. The authors compared the results with graphene samples transferred onto $\mathrm{SiO}_{2} /$ $\mathrm{Si}$ and found no significant differences, indicating that the transfer process does not significantly change the properties of graphene and hence, Raman measurements of graphene samples can be directly performed on the $\mathrm{Cu}$ foil to save time [16]. Transmission Electron Microscopy (TEM) analyses (both low magnification and high resolution) were performed with a Jeol JEM $2100 \mathrm{~F}$ by applying an accelerating voltage of $200 \mathrm{kV}$. TEM samples were prepared by following the graphene transfer route described above. In this case, the PMMA/graphene film was transferred onto holey carbon coated copper grids (200 mesh).

\subsection{Device fabrication}

P-type silicon with $300 \mathrm{~nm} \mathrm{SiO}_{2}$ layer, the resistivity of which is $\sim 0.01-0.1 \Omega \mathrm{cm}$, was used as a substrate. The $\mathrm{SiO}_{2}$ layer acts as a back-gate to be able to change the carrier density in the sample when required. First, alignment marks were created on the $\mathrm{SiO}_{2}$ $(300 \mathrm{~nm}) / \mathrm{Si}$ substrate $(5 \mathrm{~cm}$ in diameter) by photolithography. Graphene transfer process from $\mathrm{Cu}$ foils to $\mathrm{SiO}_{2}(300 \mathrm{~nm}) / \mathrm{Si}$ substrate with alignment marks was carried out by following the transfer procedure described in Section 2.1. The transferred graphene films were then etched into a Hall bar by reactive ion etching (RIE) process using oxygen plasma through a photoresist (mask) which was then removed in acetone. Two kinds of graphene Hall bars were actually designed, small ones with length $\mathrm{L}=63 \mu \mathrm{m}$ and width $\mathrm{W}=35 \mu \mathrm{m}$, and large ones with $\mathrm{L}=630 \mu \mathrm{m}$ and $\mathrm{W}=210 \mu \mathrm{m}$. Then metal electrodes (10 $\mathrm{nm}$ of $\mathrm{Pd}$ and $50 \mathrm{~nm}$ of $\mathrm{Au}$ ) were deposited through another photoresist mask using evaporation of the metal targets by Joule effect. After lift-off in acetone and cleaning, the sample was diced into small chips. Since the residual photoresist may remain on the samples, an annealing process was carried out in $10 \% \mathrm{H}_{2} / 90 \% \mathrm{Ar}$ atmosphere at $350{ }^{\circ} \mathrm{C}$ for $8 \mathrm{~h}$ (unless otherwise stated). Prior to measurements, in-situ post vacuum annealing (a few hours at $90^{\circ} \mathrm{C}$ ) was also applied.

The device's proper operation was checked before and after annealing using a two-probe test-head station at room temperature and under ambient air. Some devices were selected for further measurements at low temperature and under high magnetic field to achieve the Quantum Hall $(\mathrm{QH})$ regime, where both the longitudinal and Hall resistances were simultaneously recorded. For QH measurements, the samples were glued using silver paste on a ceramic support with gold pads. This ensured a good electrical contact of the conducting bottom face of the Si substrate with the back-gate electrode in order to control the charge carrier density in graphene. Then, wedge bonding was performed to electrically address the sample using gold wires. 


\section{Results and discussion}

\subsection{Graphene synthesis}

Low-pressure CVD growth experiments of graphene films on $\mathrm{Cu}$ foils, the carbon and oxygen content of which are different, were performed using different gas flow rates during heating to growth temperature in order to investigate the effect of heating atmosphere on the quality of the synthesized graphene films and their uniformity in terms of number of layers depending on $\mathrm{Cu}$ foil impurities.

Fig. 1(a)-(c) show FEG-SEM micrographs of 'CROP' foil subjected to CVD graphene growth process under different heating atmospheres. It was observed that heating at $300 \mathrm{sccm} \mathrm{H}$ (CROP1 sample), $200 \mathrm{sccm} \mathrm{Ar} / 100 \mathrm{sccm} \mathrm{H}_{2}$ (CROP2 sample) or hot loading the $\mathrm{Cu}$ foil directly into the preheated furnace at $1000{ }^{\circ} \mathrm{C}$ for annealing under $300 \mathrm{sccm} \mathrm{H_{2 }}$ (CROP3 sample) resulted in formation of nanometric spherical dark features on the surface. The corresponding Raman spectra of these samples (Fig. 1(d)) revealed mostly a strong D-band at $\sim 1368-1397 \mathrm{~cm}^{-1}$, which arises from breathing modes of $\mathrm{sp}^{2}$ atoms in rings and requires a defect for its activation [17,18]. All the spectra also includes a broad G-band, which corresponds to in-plane $\mathrm{C}-\mathrm{C}$ bond stretching in graphitic materials and is common to all $\mathrm{sp}^{2}$-bonded carbon systems [18]. It was observed that the G-band position shifted to higher frequencies $\left(\sim 1600 \mathrm{~cm}^{-1}\right)$ compared to that of graphene (e.g., CROP1 sample). The intensity ratio of the D-band to that of the G-band ( $I_{D} /$ $I_{G}$ ) which is generally used to characterize the defects content [18] was $\sim 0.4-0.6$, indicating that the samples were highly defective. Almost no or a weak $2 \mathrm{D}$-band with a very low $I_{2 \mathrm{D}} / I_{\mathrm{G}}$ ratio $(\sim 0.2-0.3)$ was observed in the Raman spectra of these samples, confirming that there was no monolayer graphene, but some multilayer graphene islands (Fig. 1(d)). 2D-band is attributed to a second-order process related to a phonon near the $\mathrm{K}$ point in graphene activated by double resonance process and strongly depends on any perturbation on the electronic and/or phonon structure of graphene [18].

Fig. 2(a) shows FEG-SEM micrograph of the graphene film grown on 'CROP' foil under $200 \mathrm{sccm}$ Ar flow during heating (CROP4 sample), revealing no dark spherical features across the surface. The representative Raman spectra measured at different spots across this graphene film on the $\mathrm{Cu}$ foil are shown in Fig. 2(b). Spectrum (1) revealed a negligible D-band and a high $I_{2 \mathrm{D}} / I_{\mathrm{G}}$ ratio $(\sim 2.3)$ with a symmetric 2D-band (full width at half maximum (FWHM) is $\sim 25 \mathrm{~cm}^{-1}$ ) at $2691 \mathrm{~cm}^{-1}$ and a G-band at $1589 \mathrm{~cm}^{-1}$, confirming the presence of monolayer graphene $[19,20]$. Spectrum (2) corresponds to bilayer graphene with a lower $I_{2 \mathrm{D}} / I_{\mathrm{G}}$ ratio $(\sim 1.7)$ and a broader FWHM of the 2D-band $\left(\sim 35 \mathrm{~cm}^{-1}\right)$. G-band $\left(\sim 1593 \mathrm{~cm}^{-1}\right)$ and the 2D-band $\left(\sim 2703 \mathrm{~cm}^{-1}\right)$ positions shifted to higher frequency values, and D-band was observed at $\sim 1365 \mathrm{~cm}^{-1}$ with $I_{\mathrm{D}} / I_{\mathrm{G}}$ ratio of 0.37 , as well. In spectrum (3) highly defective fewlayer or multilayer graphene was observed with $I_{\mathrm{D}} / I_{\mathrm{G}}$ and $I_{2 \mathrm{D}} / I_{\mathrm{G}}$ ratios of 1.0 and 1.1, respectively (Fig. 2(b)). The Raman analyses showed that $200 \mathrm{sccm}$ Ar flow promoted graphene growth on 'CROP' foil; however, with some non-uniformity in the number of layers across the film.

The non-graphene carbon features observed on CROP foil when only $\mathrm{H}_{2}$ was used in the heating atmosphere or if there was not enough $\mathrm{Ar}$ as a buffer gas in the $\mathrm{Ar} / \mathrm{H}_{2}$ mixture during heating were attributed to residual carbon remaining on the surface due to
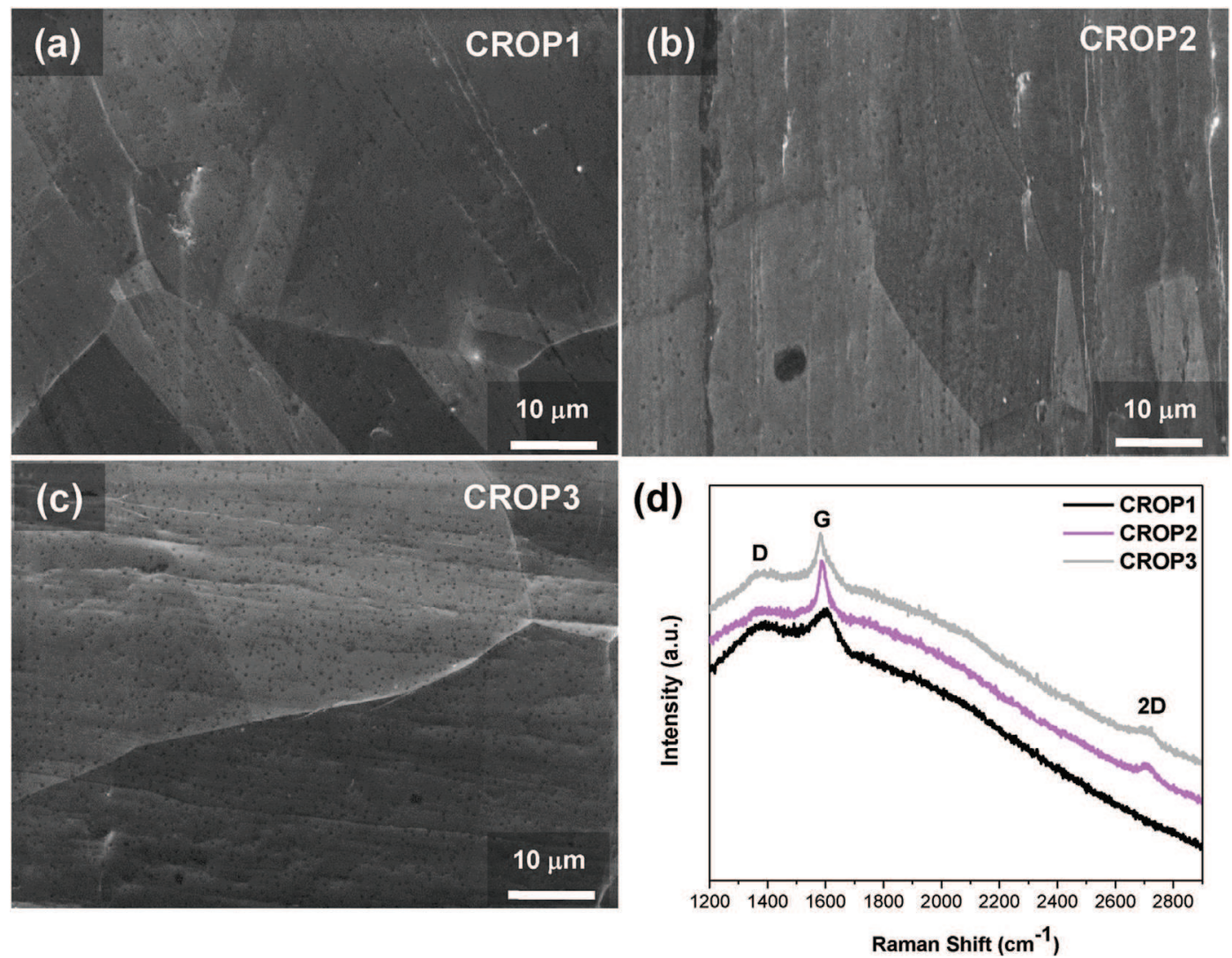

Fig. 1. FEG-SEM micrographs of 'CROP' foil after being subjected to CVD growth process under different heating conditions (a) $300 \mathrm{sccm} \mathrm{H}_{2}$ heating (CROP1), (b) $200 \mathrm{sccm}$ Ar/100 sccm $\mathrm{H}_{2}$ heating (CROP2), and (c) Hot loading the foil into a preheated furnace at $1000{ }^{\circ} \mathrm{C}$ for annealing step (CROP3). (d) Raman spectra of the samples shown in (a), (b) and (c). (A color version of this figure can be viewed online.) 

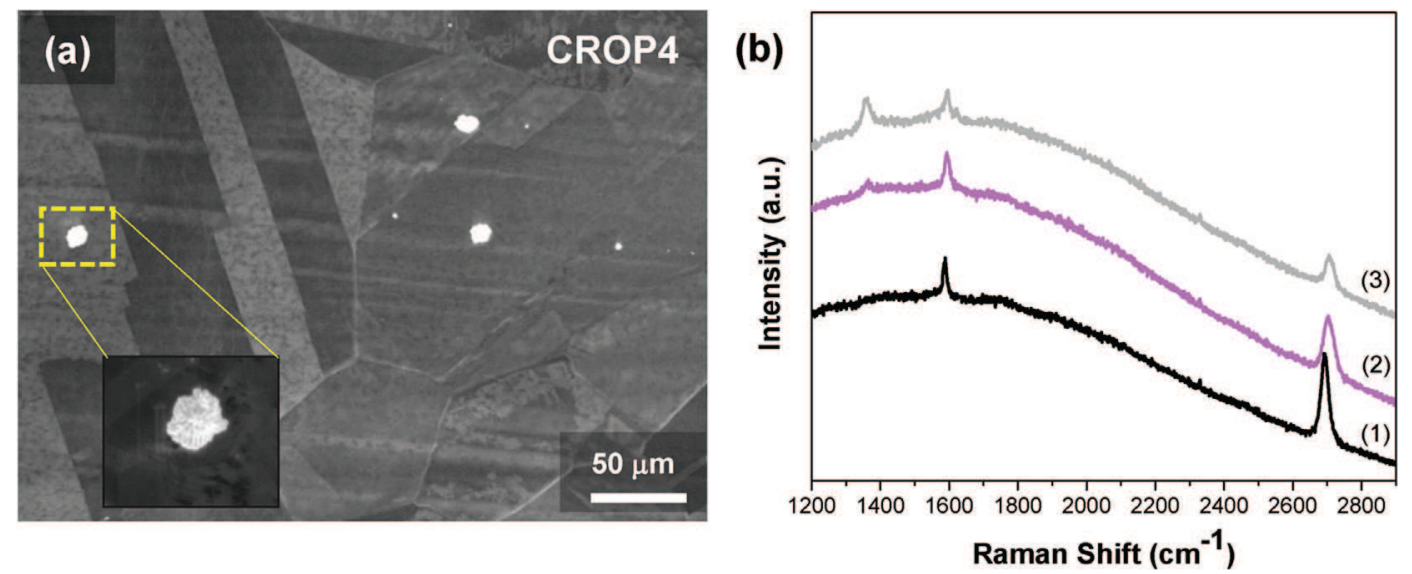

Fig. 2. (a) FEG-SEM micrograph of the graphene film grown on 'CROP' foil using $200 \mathrm{sccm}$ Ar flow during heating (CROP4 sample). Inset shows higher magnification of the impurity particle indicated by a dashed rectangle. (b) Raman spectra recorded at different spots on the CROP4 sample showing (1) Monolayer graphene, (2) Bilayer graphene and (3) Fewlayer (3-5 layers) graphene. (A color version of this figure can be viewed online.)

reacting of hydrogen with limited oxygen (either present on the foil surface or coming from the heating atmosphere), preventing the oxygen from reacting with- and removing the adventitious surface carbon. The residual carbon on the foil surface then possibly acted as active sites for graphene nucleation, forming multilayer graphene islands. It should be noted that the spherical dark features were also observed in the FEG-SEM micrographs of 'CROP' foil (precleaned using acetic acid) recorded after heating and annealing in $\mathrm{H}_{2}$ atmosphere, confirming that the carbon residues remained on the surface after annealing. When the heating was performed under Ar-only environment followed by $\mathrm{H}_{2}$ annealing, the trace amount of oxygen in Ar-gas, together with the surface oxygen on the foil surface, helped removal of carbon residues enabling graphene growth. Here, $\mathrm{Cu}$ foil surface is oxidized during heating and the following annealing under $\mathrm{H}_{2}$ environment leads to reduction of copper oxide, releasing oxygen from the surface, which then reacts with residual carbon, forming volatile carbon monoxide and carbon dioxide, and leaves a clean $\mathrm{Cu}$ surface free of unwanted carbon, as reported by Magnuson et al. [21], who found that copper with an oxidized surface can act as a self-cleaning substrate for graphene growth by CVD.

Although heating in Ar atmosphere was observed to be highly advantageous for removing residual carbon, irregular shaped, large (a few $\mu \mathrm{m}$ in diameter) impurity particles appeared on the surface in this case (Figs. 2(a) and 3). In order to investigate the composition of these impurity particles EDX analysis was performed. Fig. 3 shows the FEG-SEM micrographs of these impurities and their EDX analysis results. Both secondary electron (SE) and back scattered electron (BSE) (at the inset) images of the impurities revealed the presence of two different phases in these particles (Fig. 3(a)). EDX analyses showed that these particles consist of $\mathrm{C}, \mathrm{O}, \mathrm{Cu}$ and $\mathrm{Si}$ elements, and brighter regions are mainly $\mathrm{Cu}$-rich phase with a small amount of $\mathrm{SiO}_{2}$ (Fig. 3(b)), while darker regions contain higher amount of $\mathrm{SiO}_{2}$, as well as some copper oxide (Fig. 3(c)).

Impurity nanoparticles that appear white on the surface of the $\mathrm{Cu}$ foil after CVD graphene growth have been commonly observed during SEM analyses [7,8,11]; however, a common reason for the origin of these impurities could not be suggested. Kim et al. [7] performed EDX and Auger electron spectroscopy which showed that these white particles on the Cu surface are mostly metal particles, such as $\mathrm{Si}, \mathrm{Ca}, \mathrm{Pt}, \mathrm{Ru}$ and Ce. They suggested that there are two possibilities for the origin of these impurities. They could either come from impurities distributed inside the copper foil and be driven out to the surface during high temperature growth process or they are on the $\mathrm{Cu}$ surface even before the CVD synthesis. The authors found that the impurity particles were significantly removed when the $\mathrm{Cu}$ foil was pre-cleaned with nitric acid; therefore they concluded that the impurity particles were on the $\mathrm{Cu}$ surface from the beginning [7]. Jung et al. [11] observed $\mathrm{SiO}_{2}$ particles in the center of the carbon aggregates that were formed when only $\mathrm{H}_{2}$ was used during the annealing step of the CVD process as confirmed by EDX, and they proposed that these $\mathrm{SiO}_{2}$ particles were introduced to the sample from the quartz tube of the CVD chamber. However, their $\mathrm{SiO}_{2}$ particles were spherical and much smaller (in nanometer size) than those observed in the present study when heating was performed under only $\mathrm{Ar}$ gas. Gan and Luo [8] observed nanoparticles $(>20 \mathrm{~nm})$ in the center of the graphene hexagonal flakes and attributed them to copper oxide nanoparticles, which formed during heating of chemically polished $\mathrm{Cu}$ foil in Ar only environment (by the effect of trace amount of oxygen in $\mathrm{Ar}$ gas) and reduced to $\mathrm{Cu}$ nanoparticles by a following $\mathrm{Ar} / \mathrm{H}_{2}$ annealing. The authors suggested that heating in Ar only environment is crucial for introducing selective nucleation centers in the graphene growth step, and consequently enabling the control of graphene sizes [11].

In order to investigate the origin of the $\mathrm{SiO}_{2}$ impurities observed in the present study, CROP foil was also pre-cleaned using different cleaning procedures such as nitric acid cleaning [7] and mechanical scrubbing of the $\mathrm{Cu}$ foil surface using acetone and isopropyl alcohol (IPA) soaked tissues [22] prior to acetic acid cleaning. These foils were then subjected to CVD process at the same conditions as for the CROP4 sample (the samples pre-cleaned with nitric acid were not coded in Table 1). Fig. 4(a)-(c) show FEG-SEM micrographs of these samples. Large, anisometric impurities were observed on the foils treated by nitric acid (Fig. 4(a) and (b)), while pre-cleaning of the foil surface by acetone and IPA soaked tissues prior to acetic acid cleaning (CROP4-MC sample) helped to reduce the amount of these large, irregular shaped $\mathrm{SiO}_{2}$ impurities (Fig. 4(c)). This may indicate that some of the impurities containing Si were on the surface of the $\mathrm{Cu}$ foil prior to the CVD graphene growth process, as in agreement with Kim et al. [7]. However, it should be noted that some nanometer-sized spherical impurity particles still remain on the surface, which may indicate that some of the impurities present inside the copper foil are driven out to the surface during high temperature CVD process or they may come from the quartz tube of the CVD system. These impurities then activate the formation of graphene islands of more than one layer across the surface (Fig. 4(c)). Fig. 4(d) shows representative Raman spectra recorded 

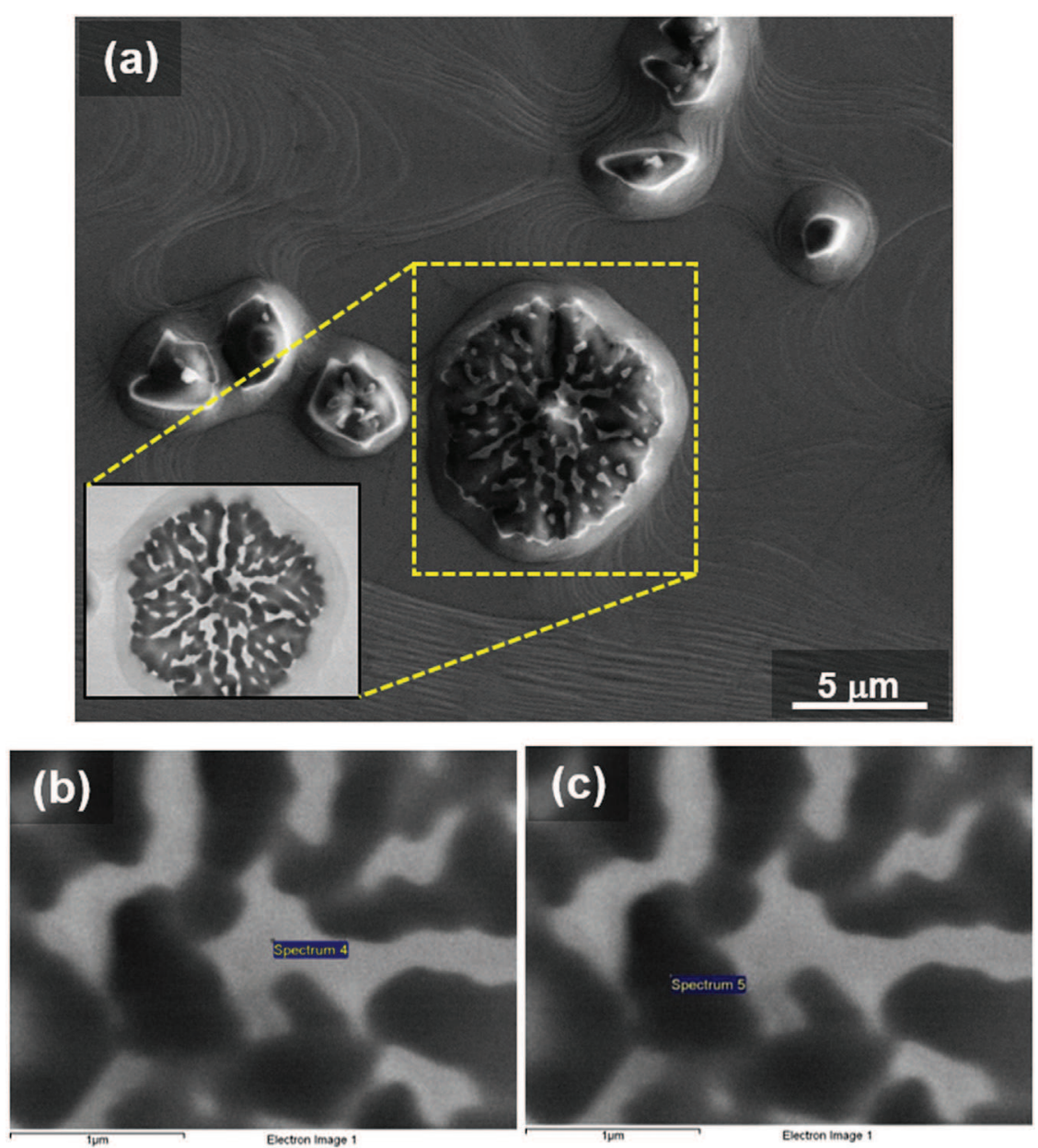

\begin{tabular}{|l|l|l|}
\hline Element & Weight\% & Atomic\% \\
\hline C K & & \\
\hline O K & 3.20 & 14.10 \\
\hline Si K & 1.74 & 5.77 \\
\hline Cu L & 9.82 & 1.56 \\
\hline & & 78.57 \\
\hline Totals & 100.00 & \\
\hline
\end{tabular}

\begin{tabular}{|l|l|l|}
\hline Element & Weight\% & Atomic\% \\
\hline $\mathrm{CK}$ & 2.89 & 7.78 \\
\hline $\mathrm{OK}$ & 22.61 & 45.66 \\
\hline $\mathrm{Si} \mathrm{K}$ & 13.53 & 15.56 \\
\hline $\mathrm{Cu} \mathrm{L}$ & 60.96 & 31.00 \\
\hline & & \\
\hline Totals & 100.00 & \\
\hline
\end{tabular}

Fig. 3. (a) Secondary electron image of impurities observed on the CROP4 sample. Inset shows the BSE image of the impurity particle indicated by a dashed rectangle, revealing the presence of two different phases. (b), (c) EDX analysis results of these two phases. (A color version of this figure can be viewed online.)

at different spots across the CROP4-MC sample transferred onto a $\mathrm{SiO}_{2}(300 \mathrm{~nm}) / \mathrm{Si}$ substrate. In Spectrum (1), a symmetrical 2D-band centered at $2676 \mathrm{~cm}^{-1}$ with a FWHM of $34 \mathrm{~cm}^{-1}$, a high intensity ratio of the 2D-band to G-band, $I_{2 \mathrm{D}} / I_{\mathrm{G}}(\sim 3.8)$, and the absence of any D-band are observed which are the signature of monolayer graphene (Fig. 4(d)) [19,20]. On the other hand, observation of a larger 2D-band at $2685 \mathrm{~cm}^{-1}$ with a FWHM of $42 \mathrm{~cm}^{-1}$, a decreased $I_{2 \mathrm{D}} / I_{\mathrm{G}}$ ratio $(\sim 2.8)$ and the presence of a small D-band $\left(I_{\mathrm{D}} / I_{\mathrm{G}}: \sim 0.09\right)$ in Spectrum (2) confirm the presence of bilayer graphene. This is in agreement with the SEM micrographs in Fig. 4(c) that there are bilayer islands on the monolayer graphene film. High resolution TEM (HRTEM) images of the CROP4-MC sample reveal the impurity nanoparticles ( $5 \mathrm{~nm}$ in diameter) on the graphene film (Fig. 4(e) and (f)). Fast Fourier transform (FFT) of the dashed area revealed hexagonal spot patterns indicating the six-fold symmetry feature of graphene (Inset in Fig. 4(e)). A higher magnification image shows the impurity nanoparticles more clearly (Fig. 4(f)). The corresponding FFT of this image (at the inset) revealed the contribution of these nanoparticles, as well as graphene.

These preliminary results indicated that the $\mathrm{SiO}_{2}$ impurities most probably originated from the $\mathrm{Cu}$ foil itself and were promoted to form in different shapes and sizes depending on the heating atmosphere and pre-cleaning of the $\mathrm{Cu}$ foil. In order to investigate the origin of these impurities further and whether their amount may vary from batch to batch, CVD graphene growth experiments were also performed on 'CPOR' foil (the foil with the same lot number, but belonging to a different batch). FEG-SEM micrograph of the 'CPOR' foil, pre-cleaned using acetic acid for $10 \mathrm{~min}$, subjected to CVD process under $200 \mathrm{sccm}$ Ar flow during heating (CPOR4 sample - the graphene synthesis conditions are same as for the CROP4 sample) revealed the appearance of much higher amount of impurities with irregular shape (Fig. 5(a)). EDX analysis 

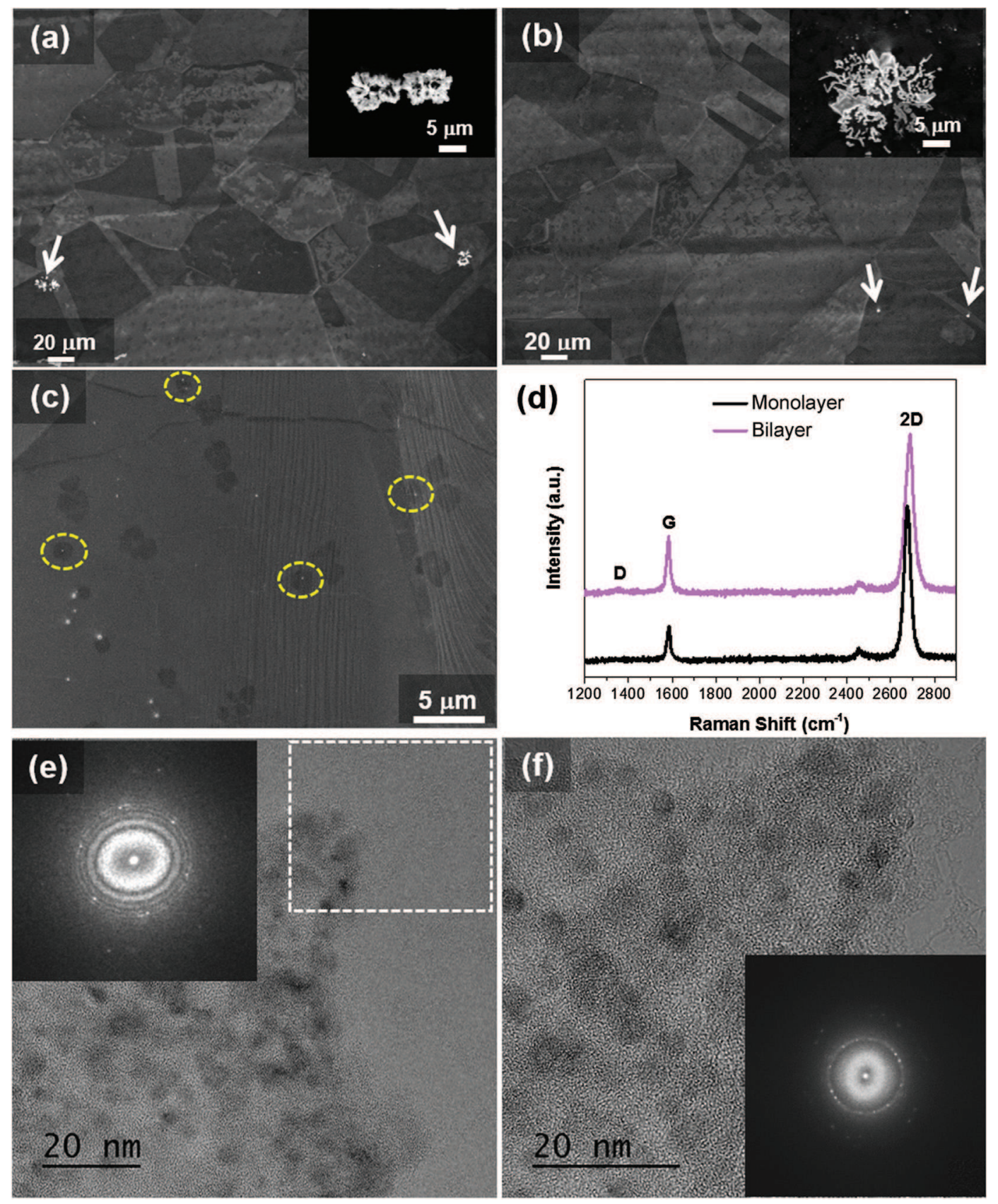

Fig. 4. FEG-SEM micrographs of the graphene samples that were grown on the Cu foils pre-cleaned by (a) Nitric acid for $30 \mathrm{~s}$, (b) Nitric acid for $60 \mathrm{~s}$, and (c) Mechanical scrubbing of the foil surface using acetone and IPA soaked tissues (CROP4-MC sample). Dashed circles indicate the nm size impurities that activate the growth of graphene with more than one layer. Insets in (a) and (b) show higher magnification of the impurities (indicated by arrows) observed on the surface. (d) Representative Raman spectra (recorded at different spots) of the graphene film shown in (c), revealing the presence of bilayers, as well as monolayer graphene. (e) HRTEM image of the graphene film shown in (c) after transfer from the Cu foil. Impurity nanoparticles are present on the graphene film. Inset shows the FFT of the area showed by a dashed square, indicating six fold symmetry of graphene. (f) Higher magnification of (e). Inset shows the FFT of the corresponding HRTEM image, revealing the contribution of nanoparticles, as well as graphene. (A color version of this figure can be viewed online.)

of an impurity particle showed the presence of $\mathrm{C}, \mathrm{O}, \mathrm{Si}$ and $\mathrm{Cu}$, similar to the composition of the impurities observed on the 'CROP' foil, confirming that the impurities were $\mathrm{SiO}_{2}$ particles with some copper oxide regions around them (Fig. 5(b)). It should be noted that these $\mathrm{SiO}_{2}$ particles were transferred onto the $\mathrm{SiO}_{2} / \mathrm{Si}$ substrate together with the graphene film (Fig. 5(c) and (d)).

Fig. 6(a) and (b) show the FEG-SEM micrographs of graphene films grown on 'CPOR' foil using $300 \mathrm{sccm} \mathrm{H}_{2}$ (CPOR1 sample) and $200 \mathrm{sccm} \mathrm{Ar} / 100 \mathrm{sccm} \mathrm{H} \mathrm{H}_{2}$ (CPOR2 sample) during heating, respectively. In contrast to CROP1 and CROP2 samples, very few and almost no carbon residues were observed on the CPOR1 and CPOR2 sample surfaces, respectively. Although it could be expected to observe lower carbon residues on the CPOR foil due to its lower adventitious carbon content in comparison to the CROP foil, the main reason for obtaining a clean surface without any carbon residues could be attributed to higher surface oxygen content of the CPOR foil. Oxygen reacts with and removes unwanted carbon absorbents during heating and annealing. This is also in agreement 


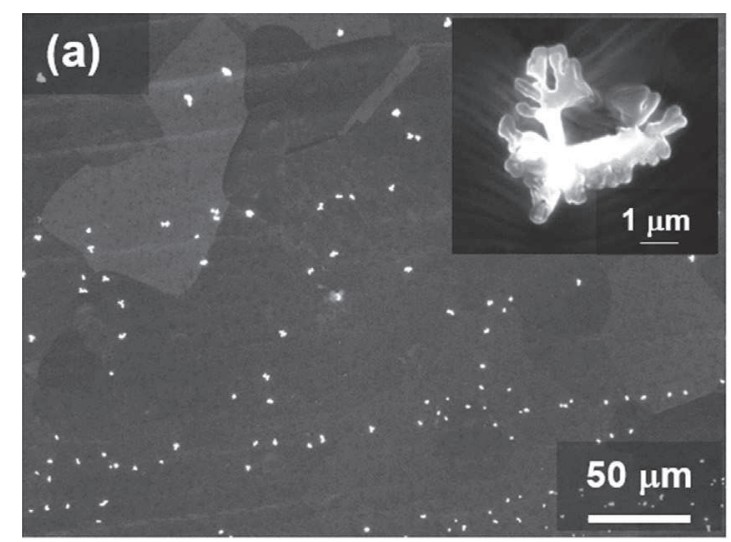

(b)

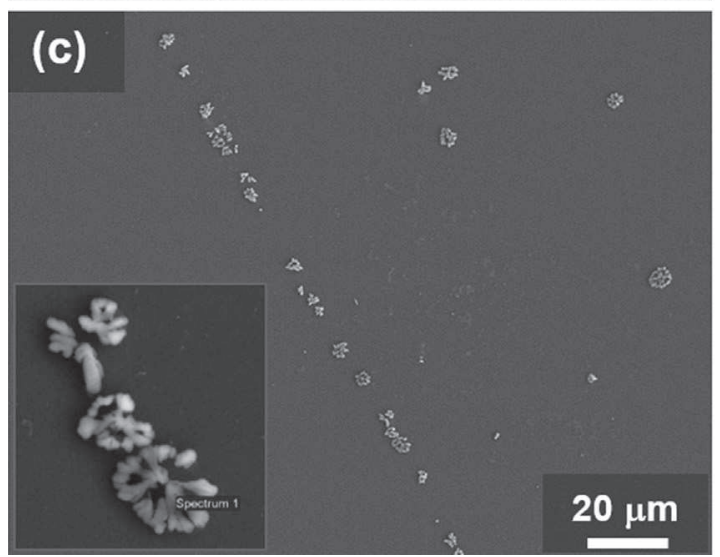

(d)

\begin{tabular}{|l|l|l|}
\hline Element & Weight\% & Atomic\% \\
\hline & & \\
\hline $\mathrm{C} \mathrm{K}$ & 2.24 & 4.93 \\
\hline $\mathrm{OK}$ & 34.92 & 57.71 \\
\hline $\mathrm{Si} \mathrm{K}$ & 21.35 & 20.10 \\
\hline $\mathrm{Cu} \mathrm{L}$ & 41.48 & 17.26 \\
\hline Totals & 100.00 & \\
\hline
\end{tabular}

\begin{tabular}{|l|l|l|}
\hline Element & Weight\% & Atomic\% \\
\hline O K & 45.72 & 59.65 \\
\hline Si K & 54.28 & 40.35 \\
\hline & & \\
\hline Totals & 100.00 & \\
\hline
\end{tabular}

Fig. 5. (a) FEG-SEM micrograph of the CPOR4 sample on Cu foil, revealing the impurity particles on the surface. Inset shows higher magnification of an impurity particle. (b) EDX result of the corresponding impurity particle shown at the inset in (a). (c) FEG-SEM micrograph of CPOR4 sample transferred onto a $\mathrm{SiO}_{2}$ (300 nm)/Si substrate. The impurity particles were also transferred together with the graphene film. (d) EDX analysis result of an impurity particle (shown at the inset in (c)).
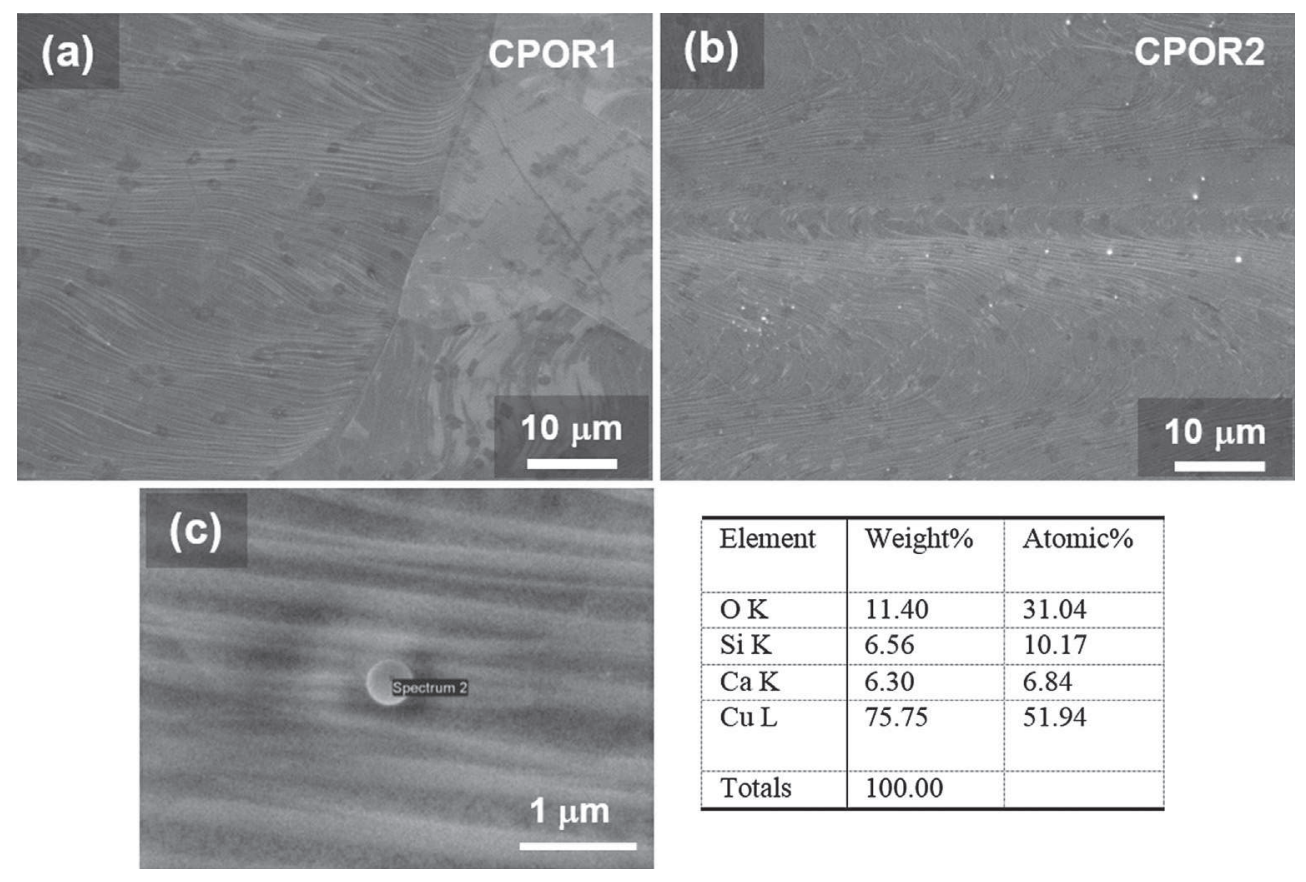

\begin{tabular}{|l|l|l|}
\hline Element & Weight\% & Atomic\% \\
\hline O K & 11.40 & 31.04 \\
\hline Si K & 6.56 & 10.17 \\
\hline $\mathrm{Ca} \mathrm{K}$ & 6.30 & 6.84 \\
\hline $\mathrm{Cu} \mathrm{L}$ & 75.75 & 51.94 \\
\hline Totals & 100.00 & \\
\hline
\end{tabular}

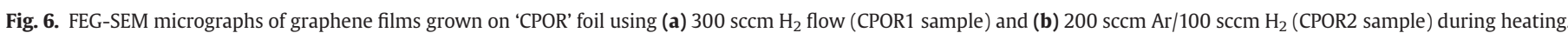
(c) EDX analysis result of a spherical impurity nanoparticle observed in (b).

with Magnuson et al. [21], who observed much less carbon residue on oxygen-rich $\mathrm{Cu}$ compared to oxygen-free $\mathrm{Cu}$ after annealing at
$1040{ }^{\circ} \mathrm{C}$ for $1 \mathrm{~h} \mathrm{H}_{2}$ annealing and attributed this to the oxygen present in oxygen-rich $\mathrm{Cu}$. It should be noted that Raman analyses 


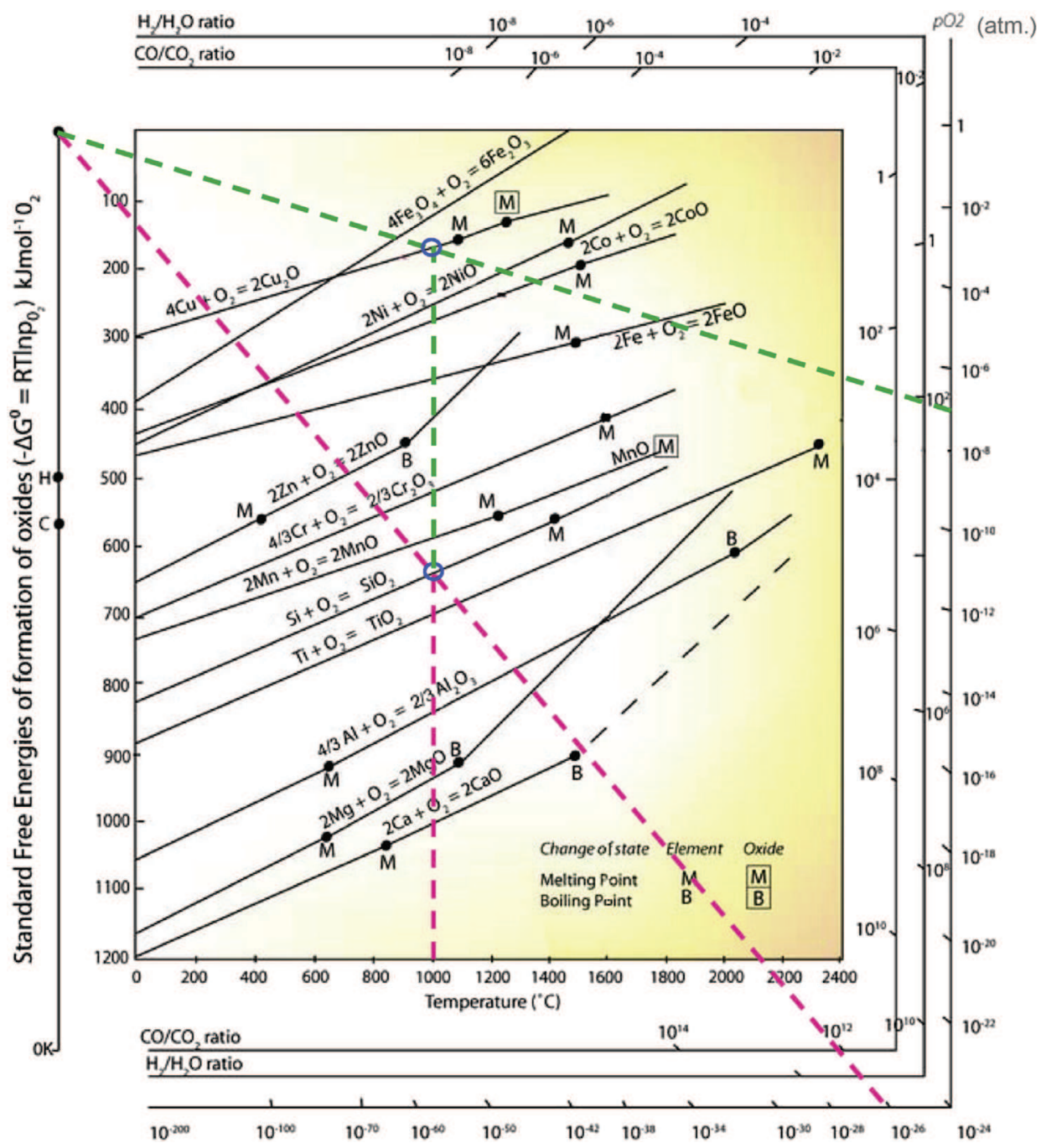

Fig. 7. Standard free energies of formation of oxides as a function of temperature ${ }^{1}$ [23]. (A color version of this figure can be viewed online.)

of the CPOR1 sample (not shown) revealed the presence of fewlayer and multilayer graphene regions in this sample. FEG-SEM micrographs of the CPOR1 and CPOR2 samples also showed that these samples did not exhibit irregular shaped large $\mathrm{SiO}_{2}$ particles, in contrast with the case when heating was performed only in $\mathrm{Ar}$ flow (Fig. 6(a) and (b)). These results are in agreement with those observed for the 'CROP' foil, confirming that the irregular-shaped, large $\mathrm{SiO}_{2}$ particles were formed when the heating was carried out in Ar only environment. However, spherical impurity nanoparticles were observed especially on the $\mathrm{Ar} / \mathrm{H}_{2}$ heated sample. Fig. 6(c) shows the EDX analysis result for one of these nanoparticles, indicating that it contained $\mathrm{O}, \mathrm{Si}, \mathrm{Ca}$ and $\mathrm{Cu}$ elements. The presence of oxygen also indicates the presence of oxides in these nanoparticles. The observation of Ca both in the as-received CPOR foil (XPS spectrum in Fig. S2) and in the sample after the CVD process indicated that this impurity could not be eliminated during pre-cleaning of the $\mathrm{Cu}$ foil or at the temperature that the CVD process was performed. However, in contrast to XPS spectrum, no 'P' was observed in the EDX result, indicating the removal of this impurity during pre-graphene growth steps.

The $\mathrm{SiO}_{2}$ impurity appearance in the present study could be attributed to oxidation of $\mathrm{Si}$ impurities that were already present in the as-received $\mathrm{Cu}$ foil due to presence of residual $\mathrm{O}_{2}$ in the heating atmosphere when it contains only Ar gas. In order to prevent oxidation, the oxygen partial pressure of the atmosphere must be below a specific level, which is required to form an oxide. The oxygen partial pressure, above which oxidation occurs is known for each metal and can be determined by using the corresponding Ellingham diagram, which gives the standard free energies of formation of oxides as a function of temperature [23]. As determined from the Ellingham diagram (Fig. 7), Si oxidizes at any oxygen partial pressure $\left(\mathrm{pO}_{2}\right)$ higher than $\sim 10^{-26}$ atm $\left(7.6 \times 10^{-24}\right.$ Torr $)$ at $1000^{\circ} \mathrm{C}$. Using an inert gas such as Ar decreases the oxygen level in the atmosphere significantly; however, even 99.999\% pure Ar still contains $1-2$ ppm of oxygen, which is enough to oxidize Si. In order to reduce the oxygen level further, it is necessary to react it with hydrogen:

$1 / 2 \mathrm{O}_{2}+\mathrm{H}_{2} \rightarrow \mathrm{H}_{2} \mathrm{O}$

In this case, the oxygen partial pressure depends on the $\mathrm{H}_{2}: \mathrm{H}_{2} \mathrm{O}$ ratio. Accordingly, if this ratio is higher, the atmosphere becomes more reducing.

Zhu et al. [24] have studied floating zone refining of commercially available $99.9999 \%$ pure $\mathrm{Cu}$ under reduced hydrogen

\footnotetext{
1 http://www.doitpoms.ac.uk/tlplib/ellingham_diagrams/printall.php.
} 
pressure. They observed $\mathrm{SiO}_{2}$ inclusions in the molten zone and concluded that these inclusions originate from the starting material. The authors reported that if $\mathrm{Si}$ is present as a solid solution in the starting material, in order to reduce the amount of it below $0.005 \mathrm{ppm}$, the oxygen partial pressure in the chamber should be higher than $1.6 \times 10^{-17} \mathrm{~atm}$. $\left(1.216 \times 10^{-14} \mathrm{Torr}\right)$ at $1473 \mathrm{~K}$ [24]. However, they determined that oxygen partial pressure in the hydrogen atmosphere is only $1.3 \times 10^{-25} \mathrm{~atm}$. $\left(9.88 \times 10^{-23} \mathrm{Torr}\right)$ at $1473 \mathrm{~K}$. Therefore, the authors concluded that the $\mathrm{SiO}_{2}$ inclusions are not due to the reaction of Si with trace oxygen in liquid copper during refining in hydrogen atmosphere, but come from the starting material [24]. Lim et al. [25] carried out experiments to remove impurities from $\mathrm{Cu}$ metal by $\mathrm{Ar}$ and $\mathrm{Ar}-20 \% \mathrm{H}_{2}$ plasma arc melting. Impurity concentrations in the $\mathrm{Cu}$ metal after refining were determined by glow discharge mass spectroscopy and it was shown that the oxygen content of the starting material increased from 15 to 33.5 (mass) ppm after 60 min Ar treatment, but decreased to 6.8 (mass) ppm after $\mathrm{Ar}-20 \% \mathrm{H}_{2}$ plasma arc melting for $60 \mathrm{~min}$, indicating that the Ar introduces oxygen into the system [25]. The concentration of $\mathrm{Si}$ showed a slight decrease from 0.31 to $0.28 \mathrm{ppm}$ after Ar plasma arc melting, while $\mathrm{Ar}-20 \% \mathrm{H}_{2}$ was found to be slightly more effective with a Si concentration of 0.22 after refining. The authors reported that $\mathrm{Si}$ impurities in molten $\mathrm{Cu}$ metal cannot be separated easily due to the formation of $\mathrm{SiO}_{2}$ inclusions in the starting material itself [25].

The $\mathrm{Cu}$ foil impurities affect not only the quality but also the catalytic decomposition of $\mathrm{CH}_{4}$, consequently the thickness uniformity of the grown graphene film, since the impurities enhance the catalytic activity of the $\mathrm{Cu}$ surface [5]. As it can be seen in Fig. 6(a) and (b), the impurity nanoparticles promote nucleation of
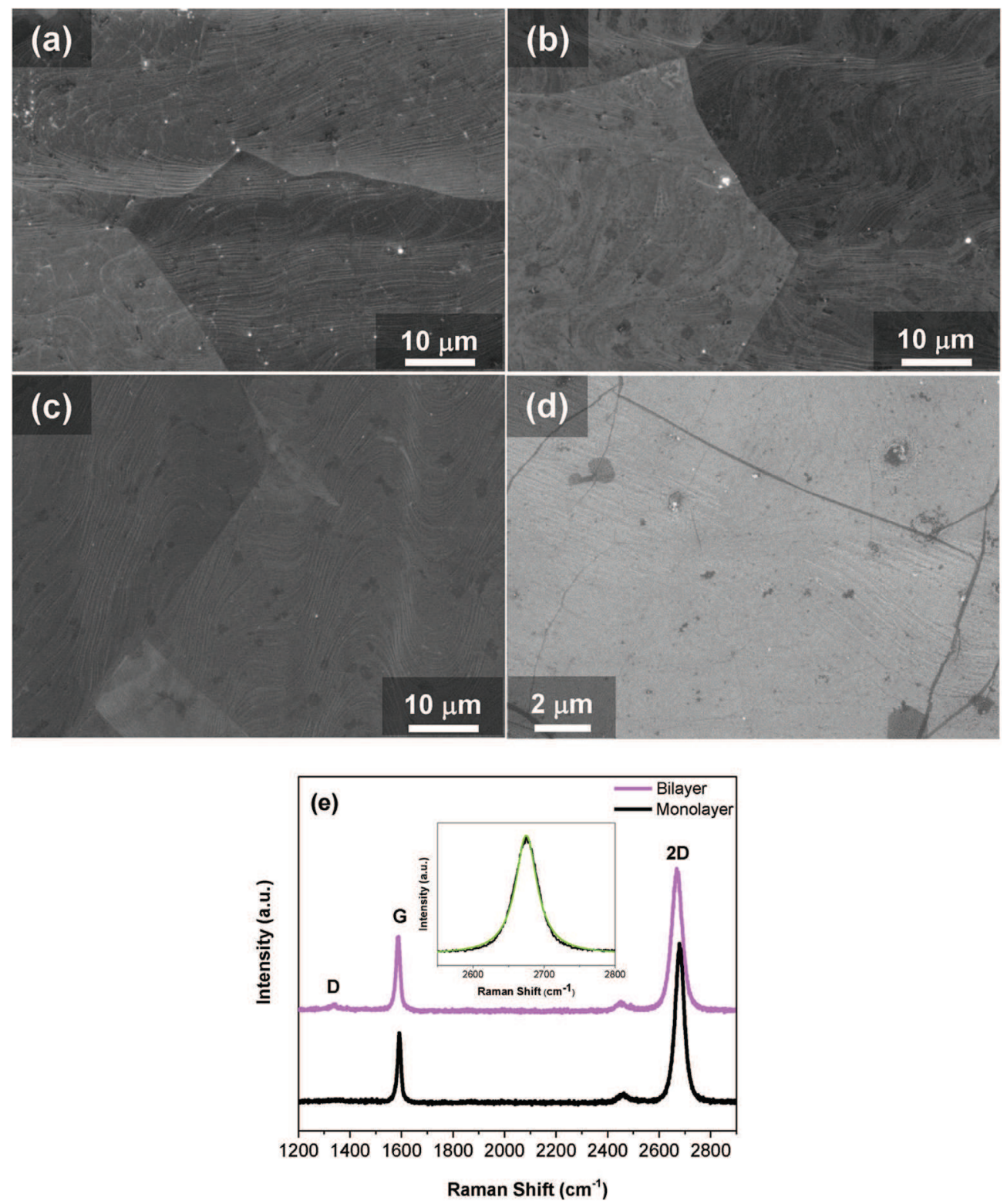

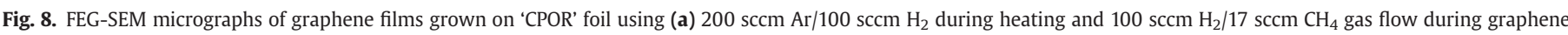
growth (CPOR3 sample), (b) the same process conditions as indicated in (a), but at a 0.3 and 0.2 Torr during heating and annealing, instead of 0.5 Torr. The Cu foil was mechanically cleaned prior to acetic acid cleaning (CPOR3-MC sample), and (c) the same conditions as indicated in (b), but the Cu foil was pre-cleaned in a nitric acid solution for $60 \mathrm{~s}$ instead of acetic acid (CPOR3-NA sample). (d) FEG-SEM micrograph of the CPOR3-NA sample transferred onto a $\mathrm{SiO}_{2}$ (300 nm)/Si substrate. (e) Representative Raman spectra recorded at different spots across the CPOR3-NA sample. Inset shows the single Lorentzian fit of the 2D-band of monolayer graphene. (A color version of this figure can be viewed online.) 
more than one layer graphene islands on the surface (the darker regions). Therefore, to improve the thickness uniformity of CVD grown graphene films, it is critical to control the process parameters, as well as to minimize the amount of impurities. In order to examine the effect of $\mathrm{CH}_{4}$ concentration on thickness uniformity of graphene film, 'CPOR' foil was subjected to graphene growth using $100 \mathrm{sccm} \mathrm{H}_{2} / 17 \mathrm{sccm} \mathrm{CH}$ gas flow for 5 min by fixing the other parameters constant as in the CPOR2 sample (CPOR3 sample). FEGSEM micrograph of this sample indicated that decreasing the $\mathrm{CH}_{4}$ concentration resulted in a decrease in the amount of graphene islands with more than one layer that appear in a darker color with respect to monolayer graphene (Fig. 8(a)). Using mechanically cleaned 'CPOR' foil prior to acetic acid cleaning, and decreasing the process pressure from 0.5 Torr to $\sim 0.3$ and $\sim 0.2$ Torr for the heating and annealing steps, respectively resulted in a smoother surface (CPOR3-MC sample) (Fig. 8(b)). When 'CPOR' foil was cleaned by using nitric acid solution $(5.4 \%(\mathrm{w} / \mathrm{w})$ ) for $60 \mathrm{~s}$ after mechanical cleaning (CPOR3-NA sample), a cleaner $\mathrm{Cu}$ foil surface with a significantly reduced impurity and bilayer/few-layer island amounts was observed compared to CPOR3-MC sample (Fig. 8(c)). The FEG-SEM micrograph of the CPOR3-NA sample transferred onto a $\mathrm{SiO}_{2} / \mathrm{Si}$ substrate reveals these bilayer islands, as well as the grain boundaries and the wrinkles across the surface (Fig. 8(d)). Fig. 8(e) shows representative Raman spectra recorded at different spots across the CPOR3-NA sample. A symmetrical 2D-band that can be fitted with a single Lorentzian (as shown in the inset) centered at $2679 \mathrm{~cm}^{-1}$ with a FWHM of $38 \mathrm{~cm}^{-1}$, a high intensity ratio of the $2 \mathrm{D}$-band to $\mathrm{G}$-band, $I_{2 \mathrm{D}} / I_{\mathrm{G}}(\sim 2.3)$ and an almost negligible D-band are all the hallmarks of single layer graphene $[19,20]$. On the other hand, Raman spectrum (recorded at a different spot) with a larger 2D-band (FWHM of $46 \mathrm{~cm}^{-1}$ ) at $2674 \mathrm{~cm}^{-1}$, a lower $I_{2 \mathrm{D}} / I_{\mathrm{G}}$ ratio $(\sim 1.9)$ and a small D-band $\left(I_{\mathrm{D}} / I_{\mathrm{G}}\right.$ : $\sim 0.04$ ) was also observed, confirming that the islands observed on the corresponding FEG-SEM micrographs (Fig. 8(c) and (d)) were bilayer graphene. Fig. 9 shows low magnification TEM and HRTEM images of a bilayer graphene island on CPOR3-NA sample. The number of layers of this island can be easily observed at the edge (Fig. 9(b)). HRTEM image shows high crystallinity of the sample (Fig. 9(c)), and the FFT image of this HRTEM micrograph reveals hexagonal spot patterns indicating the six-fold symmetry feature of graphene (Fig. 9(d)).

\subsection{Device fabrication and Quantum Hall measurements}

The electrical characterization of the two samples (CROP4-MC and CPOR3-NA) was performed at room temperature.

The $\mathrm{R}(\mathrm{Vg})$ characteristic of CROP4-MC sample exhibited a resistance of the order of $6 \mathrm{k} \Omega$ (not shown); however, the Dirac point (the maximum resistance) was out of the experimental range and the resistance peak was quite broad, which is typical of disordered graphene with low electronic mobility. The Dirac point could not be recovered even after $\mathrm{Ar} / \mathrm{H}_{2}$ annealing at $350{ }^{\circ} \mathrm{C}$. It is worth noting that since the sample was put back to air after annealing, re-contamination certainly occurred and the benefits of $\mathrm{Ar} / \mathrm{H}_{2}$ annealing were strongly limited.

Next, we focus on another device (CPOR3-NA sample), which
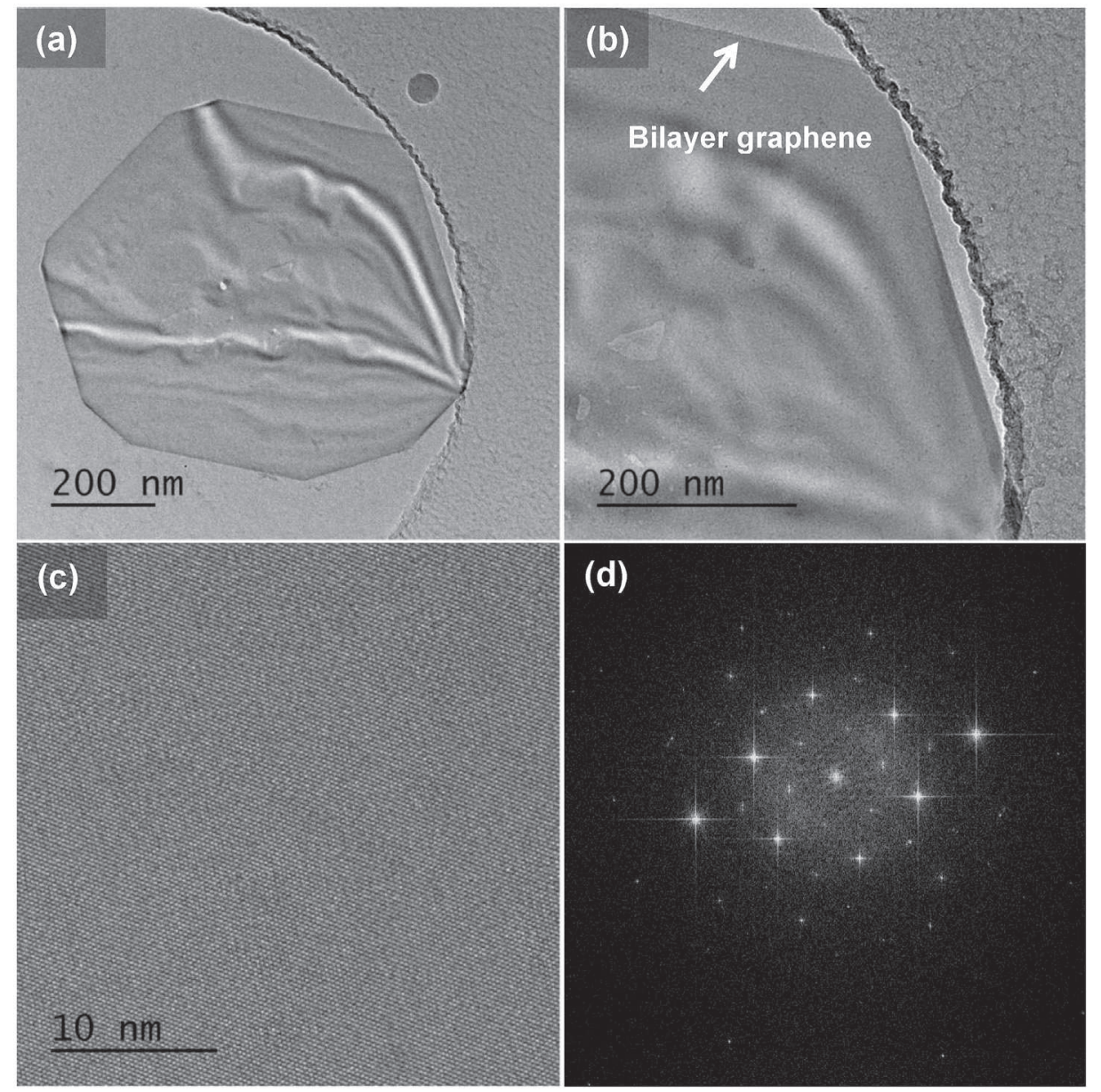

Fig. 9. (a), (b) Low magnification TEM and (c) HRTEM images of a bilayer graphene island on the CPOR3-NA sample and (d) FFT of the corresponding HRTEM image shown in (c). 
was exposed to vacuum annealing only. The electrical resistivity of this sample was estimated to range between $2.8 \mathrm{k} \Omega$ and $19.5 \mathrm{k} \Omega$. The charge neutrality point (CNP) was located at $V_{g} \sim 27 \mathrm{~V}$ indicative of residual n-doping. The longitudinal $\mathrm{R}_{\mathrm{XX}}(\mathrm{B})$ and Hall $\mathrm{R}_{\mathrm{XY}}(\mathrm{B})$ resistances were recorded as a function of magnetic field for selected values of the back-gate voltage, as shown in Fig. 10(a) and (b), respectively. $R_{X X}(B)$ shows periodic oscillations when plotted vs $1 /$ $\mathrm{B}$, the period of which being related to the charge carrier density. When the graphene device was driven close to the CNP, $\mathrm{R}_{\mathrm{XX}}(\mathrm{B})$ diverged for high field which is typical for a quantum Hall insulator. On the other hand, the Hall resistance shows well defined quantized plateaus at $\mathrm{R}_{\mathrm{XY}}(\mathrm{B})=\mathrm{h} / 2 \mathrm{e}^{2}=12.9 \mathrm{k} \Omega$ and $\mathrm{h} / 6 \mathrm{e}^{2}=4.3 \mathrm{k} \Omega$ that is typical for monolayer graphene. Hence, despite the eventual presence of bilayer patches, the whole device behaves as monolayer graphene when considering its electronic properties only. Notice that the Hall resistance is negative for electron-doping $\left(\mathrm{V}_{\mathrm{g}}>\mathrm{V}_{\mathrm{CNP}}\right)$ and positive for hole doping $\left(\mathrm{V}_{\mathrm{g}}<\mathrm{V}_{\mathrm{CNP}}\right)$ which establishes its ambipolar behavior. In the vicinity of the CNP, the welldefined Hall resistance plateaus were quenched due to the presence of electron-hole puddles (which is typical for graphene deposited on $\mathrm{Si} / \mathrm{SiO}_{2}$ substrate) (Fig. $10(\mathrm{c})$ ). Such local and inhomogeneous doped regions (puddles), induced by the substrate, contribute as an extrinsic source of disorder and are partly responsible for the fairly low mobility in this device, measured to $\sim 320 \mathrm{~cm}^{2} /$ V.s at $4.2 \mathrm{~K}$ and for $\mathrm{n} \sim 2.80 \times 10^{12} \mathrm{~cm}^{-2}$.

\section{Conclusions}

Low-pressure CVD growth synthesis of graphene films on two

a)

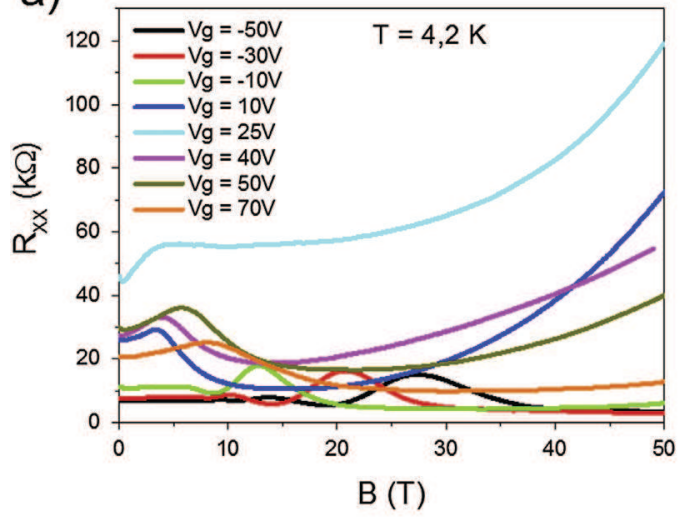

different $\mathrm{Cu}$ foils, belonging to two different batches of the same commercial source, but the surface oxygen and carbon contents of which are different, was performed by controlling the $\mathrm{H}_{2}$ and/or $\mathrm{Ar}$ flows rates during heating up to growth temperature. The effects of heating atmosphere on graphene growth, quality of the synthesized graphene films and final impurity level were investigated depending on the $\mathrm{Cu}$ foil impurities.

The non-graphene carbon features (residual carbon) were observed on carbon-rich, but oxygen-poor (CROP) Cu foil, when only $\mathrm{H}_{2}$ was used in the heating atmosphere or if there was not enough $\mathrm{Ar}$ as a buffer gas in the $\mathrm{Ar} / \mathrm{H}_{2}$ mixture. These features then acted as active sites for multilayer graphene growth. Heating this foil in $\mathrm{Ar}$ only environment followed by $\mathrm{H}_{2}$ annealing helped removal of carbon residues, enabling graphene growth. On the other hand, almost no or very few carbon residues were observed on the carbon poor, but oxygen-rich (CPOR) $\mathrm{Cu}$ foil surface when the heating was performed under $\mathrm{H}_{2}$ and $\mathrm{Ar} / \mathrm{H}_{2}$ environments.

Heating in $\mathrm{Ar}$ only environment caused formation of large, irregular-shaped $\mathrm{SiO}_{2}$ impurities on both foils. The amount of these impurities was much higher on the CPOR foil compared to CROP foil. The formation of these impurities was attributed to oxidation of $\mathrm{Si}$ impurities that were already present in the $\mathrm{Cu}$ foil by the residual $\mathrm{O}_{2}$ in the heating atmosphere. The presence of $\mathrm{H}_{2}$ in the heating atmosphere promoted high quality graphene growth without large $\mathrm{SiO}_{2}$ impurities on CPOR foil by reducing the oxygen level in the heating atmosphere. QHE measurements confirmed that the grown material behaves as monolayer graphene when considering its electronic properties, despite the presence of bilayer patches.
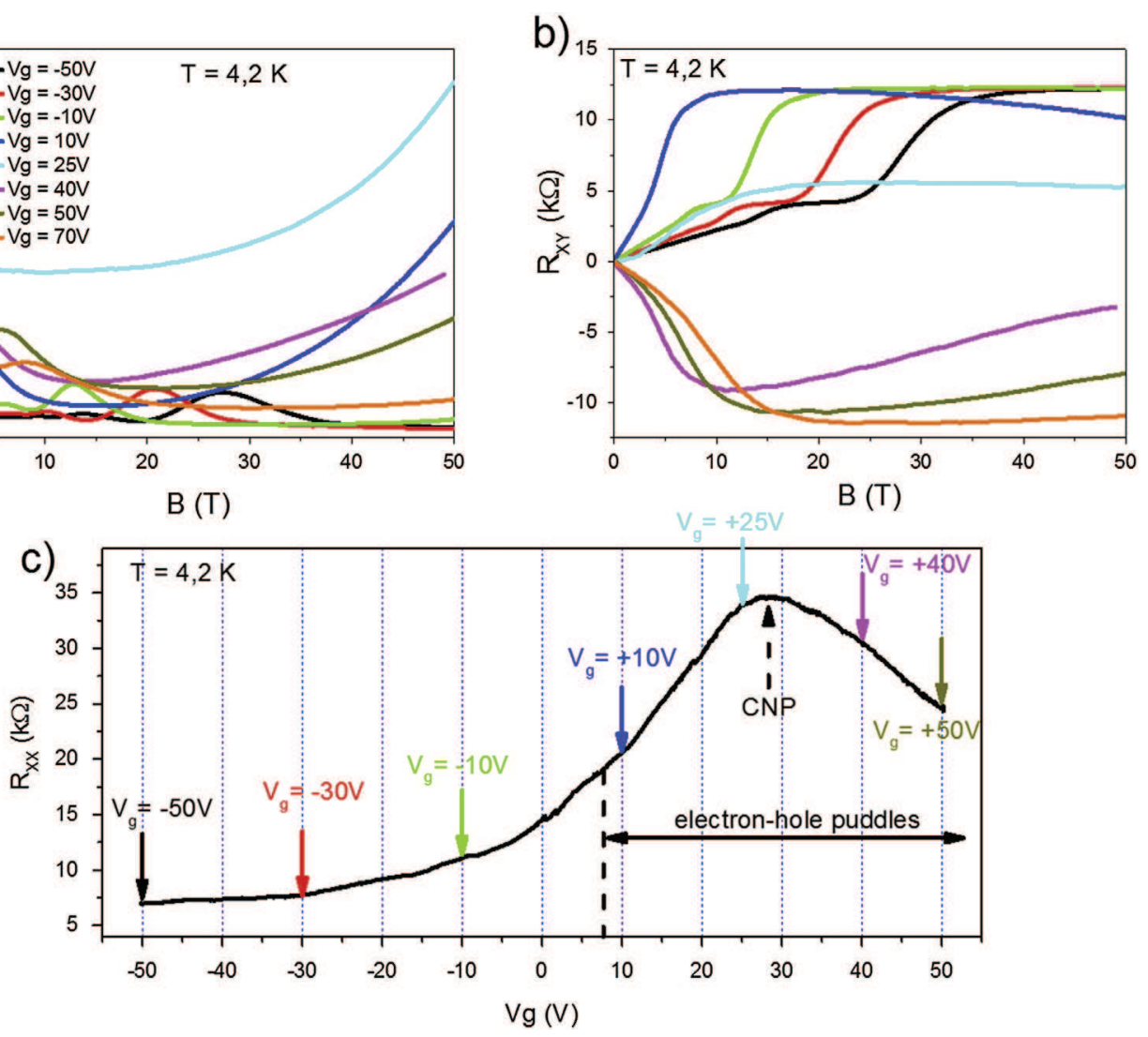

Fig. 10. (a) Longitudinal $\left(R_{x x}\right)$ and $(\mathbf{b})$ Hall $\left(R_{x y}\right)$ resistance of the CPOR3-NA sample measured as a function of magnetic field of up to $50 \mathrm{~T}$, for various values of the back-gate voltage. (c) Zero-field resistance of the CPOR3-NA sample measured at $4.2 \mathrm{~K}$ as a function of the back-gate voltage. The arrows indicate the back-gate voltages at which high magnetic field measurements have been performed (e.g., (a) and (b)). The horizontal arrow indicates the back-gate voltage range in which both electron and hole coexist. (A color version of this figure can be viewed online.) 


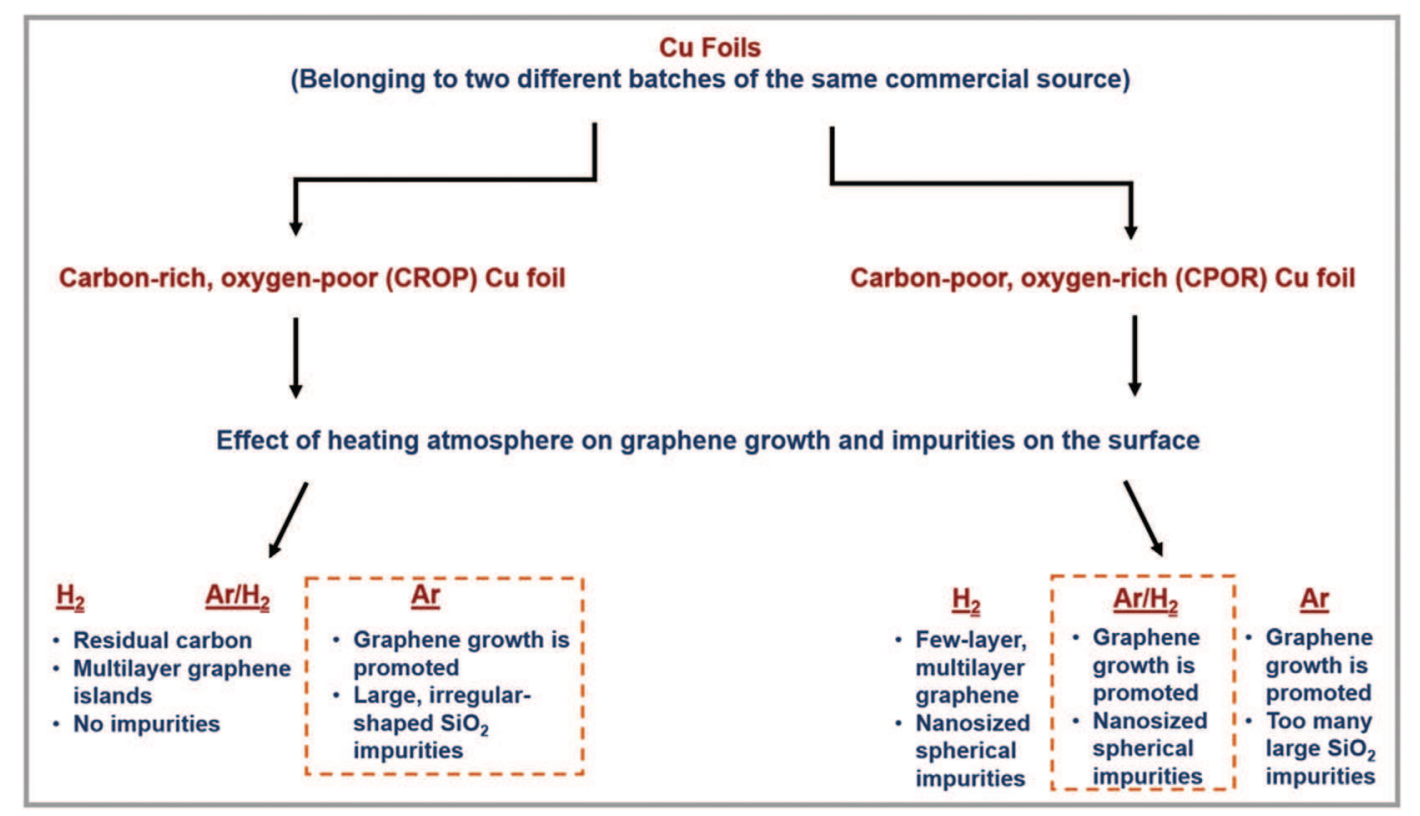

Fig. 11. Summary of the relationship between heating atmosphere and Cu foil impurities during graphene growth via low pressure CVD. (A color version of this figure can be viewed online.)

Fig. 11 gives a summary of the effect of heating atmosphere on graphene growth during low-pressure CVD method on two different $\mathrm{Cu}$ foils (belonging to different batches of the same commercial source) with different surface oxygen and carbon contents. The dashed rectangles indicate the heating atmospheres that provided the highest quality graphene growth on the corresponding $\mathrm{Cu}$ foils. It should be noted that effective pre-cleaning helped to reduce the amount of impurities on both foils.

\section{Acknowledgements}

The financial support for this study by Anadolu University Scientific Research Projects Commission (under the project numbers of 1110F155 and 1101F005) is gratefully acknowledged. The authors also thank Jerome Esvan (CIRIMAT, Toulouse) for XPS analyses and Lucien Datas for TEM analyses which were performed at R. Castaing characterization platform, UMS 3623.

\section{Appendix A. Supplementary data}

Supplementary data related to this article can be found at http:// dx.doi.org/10.1016/j.carbon.2016.08.057.

\section{References}

[1] C. Lee, X.D. Wei, J.W. Kysar, J. Hone, Measurement of the elastic properties and intrinsic strength of monolayer graphene, Science 321 (2008) 385-388.

[2] A.K. Geim, K.S. Novoselov, The rise of graphene, Nat. Mater. 6 (2007) 183-191.

[3] A.A. Balandin, S. Ghosh, W.Z. Bao, I. Calizo, D. Teweldebrhan, F. Miao, et al., Superior thermal conductivity of single-layer graphene, Nano Lett. 8 (2008) 902-907.

[4] X.S. Li, W.W. Cai, J.H. An, S. Kim, J. Nah, D.X. Yang, et al., Large-area synthesis of high-quality and uniform graphene films on copper foils, Science 324 (2009) 1312-1314.

[5] Z.Q. Luo, T. Yu, J.Z. Shang, Y.Y. Wang, S. Lim, L. Liu, et al., Large-scale synthesis of bi-layer graphene in strongly coupled stacking order, Adv. Funct. Mater 21 (2011) 911-917.

[6] H.L. Cao, Q.K. Yu, L.A. Jauregui, J. Tian, W. Wu, Z. Liu, et al., Electronic transport in chemical vapor deposited graphene synthesized on Cu: quantum Hall effect and weak localization, Appl. Phys. Lett. 96 (2010) 122106.

[7] S.M. Kim, A. Hsu, Y.H. Lee, M. Dresselhaus, T. Palacios, K.K. Kim, et al., The effect of copper pre-cleaning on graphene synthesis, Nanotechnology 24 (2013) 365602.
[8] L. Gan, Z.T. Luo, Turning off hydrogen to realize seeded growth of subcentimeter single-crystal graphene grains on copper, Acs Nano 7 (2013) 9480-9488.

[9] H.L. Zhou, W.J. Yu, L.X. Liu, R. Cheng, Y. Chen, X.Q. Huang et al., Chemical vapour deposition growth of large single crystals of monolayer and bilayer graphene, Nat. Commun. 4 (2013) 2096.

[10] Y.F. Hao, M.S. Bharathi, L. Wang, Y.Y. Liu, H. Chen, S. Nie, et al., The role of surface oxygen in the growth of large single-crystal graphene on copper, Science 342 (2013) 720-723.

[11] D.H. Jung, C. Kang, M. Kim, H. Cheong, H. Lee, J.S. Lee, Effects of hydrogen partial pressure in the annealing process on graphene growth, J. Phys. Chem. C 118 (2014) 3574-3580.

[12] Y.C. Shin, J. Kong, Hydrogen-excluded graphene synthesis via atmospheric pressure chemical vapor deposition, Carbon 59 (2013) 439-447.

[13] D.A. Shirley, High-resolution X-ray photoemission spectrum of the valence bands of gold, Phys. Rev. B 5 (1972) 4709-4714.

[14] J.H. Scofield, Hartree-Slater subshell photoionization cross-sections at 1254 and $1487 \mathrm{eV}$, J. Electron Spectrosc. Relat. Phenom. 8 (1976) 129-137.

[15] X.L. Liang, B.A. Sperling, I. Calizo, G.J. Cheng, C.A. Hacker, O. Zhang, et al., Toward clean and crackless transfer of graphene, Acs Nano 5 (2011) 9144-9153.

[16] S.D. Costa, A. Righi, C. Fantini, Y.F. Hao, C. Magnuson, L. Colombo, et al., Resonant Raman spectroscopy of graphene grown on copper substrates, Solid State Commun. 152 (2012) 1317-1320.

[17] Y. Hernandez, V. Nicolosi, M. Lotya, F.M. Blighe, Z.Y. Sun, S. De, et al., Highyield production of graphene by liquid-phase exfoliation of graphite, Nat. Nanotechnol. 3 (2008) 563-568.

[18] M.S. Dresselhaus, A. Jorio, M. Hofmann, G. Dresselhaus, R. Saito, Perspectives on carbon nanotubes and graphene raman spectroscopy, Nano Lett. 10 (2010) $751-758$.

[19] A.C. Ferrari, J.C. Meyer, V. Scardaci, C. Casiraghi, M. Lazzeri, F. Mauri, et al., Raman spectrum of graphene and graphene layers, Phys. Rev. Lett. 97 (2006) 187401.

[20] L.M. Malard, M.A. Pimenta, G. Dresselhaus, M.S. Dresselhaus, Raman spectroscopy in graphene, Phys. Rep. 473 (2009) 51-87.

[21] C.W. Magnuson, X.H. Kong, H.X. Ji, C. Tan, H.F. Li, R. Piner, et al., Copper oxide as a "self-cleaning" substrate for graphene growth, J. Mater Res. 29 (2014) 403-409.

[22] I. Vlassiouk, P. Fulvio, H. Meyer, N. Lavrik, S. Dai, P. Datskos, et al., Large scale atmospheric pressure chemical vapor deposition of graphene, Carbon 54 (2013) 58-67.

[23] H.J.T. Ellingham, Reproducibility of oxides and sulphides in metallurgical processes, J. Soc. Chem. Ind. 63 (1944) 125-133.

[24] Y.F. Zhu, K. Mimura, Y. Ishikawa, M. Isshiki, Effect of floating zone refining under reduced hydrogen pressure on copper purification, Mater Trans. 43 (2002) 2802-2807.

[25] J.W. Lim, M.S. Kim, N.R. Munirathnam, M.T. Le, M. Uchikoshi, K. Mimura, et al. Effect of $\mathrm{Ar} / \mathrm{Ar}-\mathrm{H}_{2}$ plasma arc melting on $\mathrm{Cu}$ purification, Mater Trans. 49 (2008) 1826-1829. 